\title{
LA TEORÍA RELACIONAL DE LA SOCIEDAD
}

\author{
MANUEL HERRERA GÓMEZ \\ Universidad de Granada
}

PALABRAS CLAVE ADICIONALES

Teoría Sociológica, Cambio Social,

Epistemología de las Ciencias Sociales.

\section{ADDITIONAL KEYWORDS}

Social Theory, Social Change, Epistemology of Social Sciences.

RESUMEN. El objetivo de este articulo es afrontar los fundamentos teóricos de la sociología relacional. Nos encontramos ante una forma de observar/pensar cuyo punto de partida es el siguiente: los problemas de la sociedad son problemas generados por relaciones sociales; por este motivo se propone comprenderlos $-\mathrm{y}$, si es posible, resolverlos- no sólo en función de factores individuales/voluntarios o colectivos/estructurales, sino a través de nuevas relaciones sociales y nuevas conexiones de relaciones. No resulta arriesgado decir que estamos ante una perpectiva bastante compleja. No en vano, aspira a formular una teoría y un método que sean capaces de gestionar órdenes más complejos de realidad.

ABSTRACT. The aim of this article is to address the theoretical foundations of relational sociology. We find ourselves with an observe/think format, whose point of departure is the following: problems of society are problems generated by social relationships. For this reason, the relational sociology proposes to understand them - and, if possible, to solve them-, not only as a function of individual/voluntary or collectives/structural factors, but through new social relationships and new relationship connections. It proposes a theory and method which make it possible to manage more complex orders of reality.

El objetivo de estas páginas es analizar los fundamentos teóricos de la sociología relacional. Desde un primer momento conviene puntualizar que nos encontramos ante un planteamiento que se distancia tanto de la sociología de la acción, como de la sociología de los sistemas sociales. En la primera perspectiva los fenómenos sociales son imputados a los individuos, mientras que la segunda los atribuye a los sistemas. Lo que propone la teoría relacional es

E-mail: manuel.herrera@educ.mec.es

\section{Revista Internacional de Sociología (RIS)}

Tercera Época, nº 28, Enero-Abril, 2001, pp. 5-44. 
RIS

RETISTA INTERNACIONAL DE SOCIOLOGIIA

N" 28. Enero - Abril. 2001

MINUEL HERRERA GÓNEZ

observar relaciones, pensar a través de relaciones y comprender/explicar mediante relaciones.

Como teoría, también implica una metodología propia: rechaza tanto el individualismo, como el holismo metodológico. Aún más, en cuanto teoría y metodología, la sociología relacional no representa una tercera vía, sino un punto de vista totalmente diferente. Como tal, conlleva una operatividad práctica de la sociología, es decir, una utilidad profesional que encuentra su paradigma en la intervención de redes.

\section{EL “CAMBIO RELACIONAL” EN SOCIOLOGÍA}

La sociología relacional es una forma de observar/pensar cuyo punto de partida es el siguiente: los problemas de la sociedad son problemas generados por relaciones sociales; por este motivo se propone comprenderlos $-\mathrm{y}$, si es posible, resolverlos - no sólo en función de factores individuales/voluntarios o colectivos/estructurales, sino a través de nuevas relaciones sociales y nuevas conexiones de relaciones. No resulta arriesgado decir que nos encontramos ante una perpectiva bastante compleja. No en vano, aspira a formular una teoría y un método que sean capaces de abordar órdenes más complejos de realidad'.

¿Quién debe activar tales conexiones? La respuesta es la siguiente: el observador, cualquier observador; y en primer lugar, los propios sujetos implicados, individuales y colectivos. Ahora bien, esto no es posible sin la colaboración de quien los observa en el interior de una red más amplia, red que es vital tanto para la generación, como para la posible solución de tales problemas. Cada relación (entre ego y alter) siempre tiene algunos déficits de auto-gestión. El motivo es bien sencillo: toda relación no puede activarse y observarse por sí misma; para poder obtener una mayor conformidad, necesariamente debe ser observada y sostenida por otras relaciones. Estas la observan y pueden influir desde el exterior, e incluso en el interior de un sistema relacional más general, que es la red significativa (de ego y alter).

La sociología relacional contempla la realidad desde una perspectiva que, al mismo tiempo, es difusa y específica. Me refiero a la óptica de la relacionalidad. La perspectiva es difusa porque la relación social circula por toda la sociedad. Aún más, la sociedad, en cada uno de sus ámbitos, está hecha de relaciones sociales, aunque las observemos como relaciones económicas, políticas, jurídicas, psicológicas, etc. $Y$ es específica en cuanto que la relación no se

' Sobre el significado de los conceptos de perspectiva, paradigma, teoría y método, véanse R. Boudon (1970: 201-252), P. Donati, (1985: 35-37), A. Giddens (1976) y A. Gouldner (1979). 
observa desde un punto de vista lógico, económico, político o jurídico, sino desde un punto de vista social. Esto conlleva una interpretación (o atribución de sentido) por parte de los sujetos recíprocamente implicados. Dicho en otros términos, tanto descriptiva como normativamente, no se basa en los individuos, ni en las estructuras sociales como tales, sino en las relaciones sociales - en su análisis, interpretación y valoración - como presuposiciones de los problemas y como medio para su posible solución.

Desde el punto de vista de la aplicación lo que se pretende es lo siguiente: producir, mediante la intervención de redes, un cambio que permita a los sujetos gestionar sus propias relaciones significativas (en acto o potenciales) utilizando los recursos humanos y materiales, manifestos o latentes, que aparecen en el contexto de referencia. El objetivo es realizar una auto-regulación adecuada, o por lo menos suficiente, para solucionar problemas que, de otra forma, solamente serían conceptualizados y percibidos como problemas de actores particulares o de entidades colectivas abstractas.

La sociología relacional no nace en el vacío, ni tampoco está determinada $a$ priori por una teoría cerrada, en el sentido de que esté concebida o se conciba como completa o auto-referencial ${ }^{2}$. Históricamente propone el desarrollo de una forma particular de sociedad: la sociedad relacional (Donati, 1986). Esta se caracteriza por ser (bien sea como norma o como distinción-guía) la continua generación de procesos de diferenciación y de reintegración de las relaciones sociales, tanto inter-subjetivas (redes primarias), como generalizadas (redes secundarias, impersonales y organizativas). Este tipo de sociedad requiere una visión teórico-práctica de la realidad suficientemente abierta: el pensar relacional. En estas páginas se pretenden diseñar los fundamentos teóricos generales de esta perspectiva.

La principal dificultad con la que nos enfrentamos es distanciarse de la perspectiva sistémico-funcional. No cabe duda de que esta última ha sido la que ha enfatizado con mayor fuerza el rol de las relaciones (recuerdo que al principio se hablaba de planteamiento sistémico-relacional). No en vano, ha utilizado y sigue utilizando la noción de red (network). Desafortunadamente, esta perspectiva ofrece una visión muy limitada (en dirección funcionalista) de la relación social y utiliza el concepto de red en sentido estructuralista (en mi opinión, otra simplificación inaceptable).

A lo largo de este artículo me gustaría incidir especialmente en un punto: la perspectiva relacional es diferente de la sistémico-funcionalista. El motivo es el siguiente: se constituye a partir de una presuposición general totalmente distinta.

\footnotetext{
${ }^{2}$ Como posteriormente veremos, un buen ejemplo de teoria cerrada es la teoría sistémica neo-funcionalista.
} 
En consecuencia, conlleva perspectivas teóricas y prácticas totalmente diversas. La perspectiva relacional no asume como eje el concepto de sistema, sino el de relación social, ni observa, piensa y actúa en la relación social como expresión o producto del sistema (como suelen hacer las perspectivas sistémicofuncionalistas), ni como expresión o producto de las acciones (como en las perspectivas de la acción), sino como realidad humana sui generis. Por tanto, mantiene en su interior la importancia del punto de vista de lo humano. Dicho en otros términos, sostiene una preocupación humanista, si bien dicha preocupación no se expresa en términos clásicos, es decir, como coincidencia entre lo social y lo humano, sino según procesos emergentes de diferenciación entre lo social y lo humano.

Afirmar que la relación social tiene una realidad sui generis no sólo nos pérmite distanciarnos de las teorías sistémicas y de la acción, sin tener que elegir entre una u otra; también nos abre la posibilidad de ver en las relaciones sociales una realidad que - a pesar de ser invisible, inenarrable y a menudo inciertarepresenta el substratum sobre el que se construye y se modifica la sociedad. Esto es válido tanto para la génesis, como para la búsqueda de soluciones humanas a los problemas sociales. A diferencia de los planteamientos de Luhmann, la observación relacional no es una técnica de construcción de las relaciones sociales. Mas bien es una forma de observarlas según su propio ser y hacerse, comprendiendo y explicando los senderos de su emergencia y excedencia, para poder intervenir y modificarlas, en el sentido de una auto-regulación de las relaciones observadas y actuadas por los mismos sujetos sociales.

Dicho brevemente, la sociología relacional presupone el cambio relacional de la sociedad, cambio que se ha realizado con la modernidad, pero que va más allá. Fomenta y promueve esa visión relacional de la sociedad que se inició con Marx, Durkheim, Weber y Simmel, visión que en estos autores tiene un carácter limitado y parcial. El cambio relacional consiste en la emergencia de un código simbólico particular para la diferenciación y autonomía de las relaciones (en sentido lógico, histórico y social) y el desarrollo de una relacionalidad sin precedentes, según un itinerario que, iniciado en el mundo moderno, continúa en los actuales procesos morfogenéticos de la sociedad.

\section{LOS FUNDAMENTOS DEL "PENSAR RELACIONAL"}

La emergencia de la sociedad relacional es un proceso histórico en el que se expresa y produce el tránsito del paradigma simple al paradigma complejo. Así es como lo define E. Morin desde una perspectiva ampliamente tratada en diversas obras (Morin, 1980, 1986, 1987 y 1997) ${ }^{3}$. Este proceso puede y debe ser representado como un cambio radical del status epistemológico, ontológico y 
fenomenológico de la relación social en las ciencias y en la sociedad.

Para comprender este cambio tenemos que utilizar una perspectiva que (a) permita comprender la realidad sui generis de la relación social y que (b) consiga definir el objeto del análisis y de la intervención como relación social. Estos puntos deben ser analizados con mayor detalle. A través de ellos podemos encontrar la clave de acceso para entrar en el pensar relacional.

\section{La realidad propia y sui generis de la relación social}

Decir que la relación social tiene una realidad sui generis significa decir que no es la simple derivación de algo distinto, sino que refleja un propio orden de realidad (con niveles internos) que necesita una atención particular y una gestión teórico-práctica. A su vez, este orden de realidad no es reconducible a este o aquel factor (o variable) particular (como, por ejemplo, el poder o la utilidad del intercambio), sino que es la misma relacionalidad de lo social. Esta tiene un fundamento empírico en la experiencia: así como, en el sistema de referencia orgánico, el hombre no puede existir sin aire y sin comida, en el sistema de referencia social el ser humano no puede existir sin relacionarse con los demás. Esta relación es lo constitutivo de su poder ser persona, de igual manera que el aire y la comida lo son para el cuerpo. Si anulamos la relación-con-el-otro habremos anulado la relación-consigo-mismo ${ }^{4}$. Precisamente, ésta es la materia con la que deben trabajar las ciencias sociales.

La observación sociológica puede ubicarse en dos niveles. En el primer nivel, el más elemental, se observan las relaciones, pero éstas son analizadas concentrándose en un factor o variable (por ejemplo, uno de los medios generalizados de intercambio, como el dinero, el poder o la influencia) que

\footnotetext{
${ }^{3}$ Morin, como la mayoría de los autores, piensa la relación entre simple y complejo en términos evolucionistas. Por el contrario, en mi opinión, simple y complejo son nociones totalmente relacionales. El problema no es utilizar una teoría evolucionista (la evolución siempre alude a un sistema de observación muy particular), sino más bien es ver si nuestro pensamiento está más o menos adecuado a su propio objeto. No se trata de oponer evolución y relacionalidad, sino ubicarse en un punto de vista diverso. Con el término evolución captamos ciertas selecciones relacionales.

No es extraño que los que plantean vaciar el self como "vía (como know-how) para la ética", a posteriori no manifiesten ningún interés por la sociedad (por ejemplo H. Maturana y F. Varela, 1990). La perspectiva relacional se distingue de la sistémica en lo siguiente: mientras que esta última acepta y fomenta - implícitamente o no- la implosión de las relaciones sociales, la perspectiva relacional intenta ponerlas de manifiesto. Como consecuencia, se ubica en una posición opuesta a las teorias y autores que defienden este planteamiento: para el trabajo social resulta muy dificil leer y gestionar las relaciones sociales. El resultado es orientarse hacia un planteamiento técnico (por ejemplo, farmacológico), que se centra en el individuo, de los problemas sociales.
} 
RIS

RETISTA INTERNACIONAL DE SOCIOLOGI.

N" 28. Enero - Abril. 2001

pasa de A a B y viceversa, en las oscilaciones de las interacciones y de los intercambios sociales. En el segundo nivel, el más reflexivo, no se observan los singulares factores en la relación, sino las realidades y las lógicas de las relaciones como tales; las entidades concretas, como los sujetos y los productos históricos de la sociedad (incluidas las instituciones), son observadas e interpretadas como, y a través, de relaciones sociales; en cualquier caso, una vez activada, la relación social tiene su propia autonomía.

Ciertamente, no nos encontramos con relaciones sociales dando un paseo. Pero sabemos que existen y tienen una consistencia. No sólo porque se concretan en formas, movimientos e instituciones sociales, sino también porque están presentes en nuestra experiencia. Decir que pertenecen al nivel de lo contingente no es un buen motivo para afirmar que no tienen realidad propia. El color de los ojos, por ejemplo, también posee un carácter contingente, pero tiene una realidad, ¿cuál es esta realidad? Es la realidad de una relación entre las cosas y nosotros, entre los demás y nosotros, que no es una relación lógica o meramente psíquica. La relación social se diferencia de la relación en sentido lógico y/o psíquico en cuanto que es: re-fero (referencia simbólica), re-ligo (conexión o vínculo estructural) y rel-acción (fenómeno emergente de un obrar recíproco).

Para que la relación pueda ser observada se necesita una metodología apropiada (p.eje: el esquema AGIL) (Donati, 1991: cap. 4) y una teoría del observador que se auto-observa mediante una parte tercera 5 .

Lo social es una propiedad relacional de la relación entre el observador y lo observado. Al contrario que en el terreno físico, donde la relación entre entidades materiales es un mecanismo, en el terreno social la relación es comunicativa e interpretativa: por este motivo, además de relación, hablamos de rel-acción.

\footnotetext{
${ }^{5}$ Puede ser útil, para obtener una idea más clara acerca del sentido y de la ubicación de la relación en la teoría de la auto-observación, acudir a von Foerster: "Según el principio de relatividad, que rechaza una hipótesis si ésta no vale para dos instancias contemporáneas, aunque valga para cada una separadamente (los habitantes de la Tierra y de Venus pueden ser coherentes en afirmar que están en el centro del universo, pero sus pretensiones desaparecen cuando están juntos), el solipsismo cae cuando me encuentro con otro organismo autónomo. Sin embargo, en cuanto que el principio de relatividad no es una necesidad lógica, ni una proposición que pueda ser probada como verdadera o falsa, el punto fundamental a tener presente es que yo soy libre de elegir entre adoptar este principio o rechazarlo. Si lo rechazo, yo soy el centro del universo, mi realidad son mis sueños y mis pesadillas, mi lenguaje es un monólogo y mi lógica una mono-lógica. Si lo adopto, ni yo ni el otro podemos ser el centro del universo. Como en el sistema heliocéntrico, debe ser un tercero que es el referente central. Es la relación entre tú y yo, y esta relación es identidad: realidad $=$ comunidad $i$ Cuáles son las consecuencias que se derivan en la ética y en la estética? El imperativo ético: actúa siempre con el objetivo de aumentar el número de las elecciones. El imperativo estético: si quieres ver, aprende cómo actuar" (Foerster, 1984: 307-308).
} 
Lo primero que se asume es lo siguiente: adoptar la perspectiva relacional significa colocarse en un nivel de realidad no visible, pero real. Según este nivel, la relación es el tertium, el sistema de referencia en el que debemos ubicarnos para evitar que la relatividad (de por sí inenarrable) se transforme en relativismo. Este tertium posee la misma realidad que lo que constituye nuestra identidad como comunidad, plural y pragmática. Aunque resulte dificil de comprender, la relacionalidad no sólo existe en el nivel social; también está presente en las interconexiones entre los restantes niveles de realidad (biológico, psíquico, ético, político, económico, etc.).

\section{La relación social como modalidad para definir los objetos de las disciplinas sociales}

La relación humana no sólo es un medio. También es el punto de vista donide el que analiza y actúa debe definir sus objetos, si lo que quiere es conocerlos en su naturaleza social. Cada objeto social puede (o mejor debería) ser definido en términos relacionales. Es preciso insistir en este concepto: no es correcto decir que la sociología estudia las relaciones entre hechos sociales, según la clásica expresión de V. Pareto recogida en su Tratado de Sociología General. Es mejor decir que estudia los hechos sociales como relaciones. Para conseguirlo tiene que re-definir sus objetos y sus conceptos como relaciones.

Cuando al inicio de una investigación nos planteamos el problema (por qué se tiene que...), nunca deberíamos olvidar que el fenómeno-objeto de la investigación, nace de un contexto relacional, está sumergido en un contexto relacional, da origen a un contexto o sistema relacional. El mayor error de la perspectiva fenomenológica es comenzar ubicando en epoché las relaciones sociales para re-encontrarlas como producto de la inter-sujetividad. No en vano, es algo que muy raramente consigue.

La plena asunción de estas relaciones es lo que distingue al planteamiento relacional del planteamiento fenomenológico puro. Este último coloca las relaciones sociales entre paréntesis, dando prioridad a las operaciones de la conciencia (o ego) trascendental. Resultaría absurdo negar la importancia y riqueza de esta aproximación que nace de la fenomenología, aproximación que es utilizada como momento de suspensión y recurso metodológico. Pero en las disciplinas que trabajan con lo social, la relación social es la clave de entrada en el sujeto y en el objeto que queremos conocer, y no lo contrario.

La relacionalidad social implica un código simbólico propio. Para comprender la realidad social (e intervenir en ella) es necesario aclarar la especificidad del código simbólico utilizado respecto al grado y tipo de relacionalidad que implica. Por ejemplo, los códigos de tipo binario (si-no, 0-1, interior-exterior, etc.) representan el tipo más simplificado y el grado más reducido de relacionalidad, aunque, generalmente, la simplifican a nivel micro-interactivo para exaltar 
su complejidad a nivel macro societario. Veamos el caso concreto del código binario utilizado por Luhmann, que es ciertamente útil, pero incapaz de captar la relacionalidad de los sistemas interactivos complejos a que se aplica.

Estamos ante una derivación de la primacía del subsistema económico (con su propio código funcional) y de la lógica de la competición (que es una modalidad relacional no propiamente interactiva), derivación que nos permite comprender por qué la sociología luhmanniana es tan refractaria a tratar relaciones sociales concretas. El código binario sólo tiene validez para analizar algunos fenómenos, normalmente más lógicos (o biológicos y también psíquicos), que sociológicos. No puede, por ejemplo, tratar la fenomenología de las relaciones entre público y privado sin introducir simplificaciones que pueden ser inadecuadas al objeto, o inaceptables desde una perspectiva no polarizada o no polarizable (muchos hechos sociales no son sólo de un tipo o del otro).

Por tanto, para definir el objeto en términos relacionales, la sociología necesita códigos que sean capaces de mantener abierta la complejidad en un marco más amplio de las selecciones (reducciones), que las realizadas o realizables por los códigos binarios (aut...aut). Se necesitan códigos simbólicos y modelos de análisis apropiados. Dicho en otros términos, se precisa un código simbólico que no sólo considere los términos de las relaciones. Tal código también debe tener presentes las relaciones en sí mismas, como mediaciones no reducibles a sus propios términos.

Los estudios empíricos han puesto de manifiesto que la relación está constituida por componentes diversos. Estos, a posteriori, pueden ser diferenciados del siguiente modo: el efecto de ego sobre alter (la consistencia del comportamiento de ego hacia los demás); el efecto de alter sobre ego (la consistencia en las respuestas de una persona hacia diferentes ego); el efecto de interacción (el comportamiento que ninguno de los agentes aporta a la relación, pero que resulta de la influencia recíproca entre actores particulares) (Cook y Dreyer, 1984: 679-697).

Mediante oportunas selecciones, estos efectos se pueden observar y medir. Los dos primeros pueden ser analizados a nivel individual, el tercero sólo puede observarse tomando la relación como unidad de análisis. Cada nivel de análisis se concibe como sistema y, en cuanto que cada sistema forma parte de un sistema más amplio, el nivel de análisis elegido siempre es incompleto. Cada sistema tiene que ser definido en el contexto del sistema de orden superior, y no existe un sistema final al que apelar. En consecuencia, lo que con mayor facilidad podemos observar y comprender, distinguir en sus componentes y, a partir de ello, comprender los agentes, son las relaciones.

La relación social implica unos patterns reticulares que no anulan la subjetividad y la importancia de los singulares elementos, aunque los transforman. Para el análisis y la intervención social son necesarios modelos de red que demuestren la aportación de los singulares elementos en las interacciones, así como los efectos emergentes. Desde esta perspectiva, los sistemas se presentan 
como condensaciones de redes, es decir, como modalidades concretas para leer las redes sociales.

El estudio empírico de las relaciones permite distinguir la aportación de los singulares sujetos en lo referente a los condicionamientos sociales como tales. Como dice T. Tam, la "interdependencia no es una idea circular" (Tam, 1989: 388-400). Si la centralidad de las unidades en una red social depende la una de la otra, ¿cómo podemos decir que cierta parte de la centralidad de una unidad es auto-generada? La respuesta es que, aunque nos encontremos ante una visión del mundo en la que cada individuo depende de otro, podemos separar de manera significativa la componente auto-originada de la derivada (originada por Alter). Más concretamente, el límite entre un ego y su contexto social también se puede establecer de forma precisa en un sistema completamente endógeno. La premisa fundamental de la sociología no implica que el self se pierda en el interior de la interdependencia social.

Por tanto, la lógica de red no es ni negación del sujeto, ni circularidad fenomenológica. Al contrario; es el camino para observar, describir, definir la identidad de cada agente, ahora bien, siempre teniendo en cuenta su subjetividad y evitando la circularidad indeterminada (al infinito).

\section{La relacionalidad no es relativismo, sino determinación específica}

En la actualidad, la mayoría de las ciencias sociales son relativistas, es decir, entienden la relación social como medio para disolver la propia sustancia o naturaleza de la conciencia y de los fenómenos sociales. Sin embargo, la perspectiva relacional se presenta como un modo para distanciarse del relativismo. Lo más que puede aportar la sociología a una posición no relativista es lo siguiente: o existen modelos de valores, empíricamente verificables, que son culturalmente transmitidos y limitan las posibilidades, o existen unas reglas interactivas que producen una racionalidad en los procedimientos capaz de auto-limitarse (por ejemplo a través de auto-valores y derivaciones naturales, eigen values y natural drifts). La segunda solución es la vencedora, en cuanto que la vigencia de los valores se transforma, antes o después, en etiquetas de residuos o supervivencias culturales que forman parte del pasado.

Ambas soluciones no son satisfactorias. La primera porque recurre a valores coercitivos (la contrainte de Durkheim); la segunda porque nos traslada a emergencias espontáneas o vitalistas. La primera apela a una noción de tradición cultural que conlleva numerosas insuficiencias y presenta serios límites explicativos; la segunda reduce la normatividad a algo meramente interactivo. En cualquier caso, si no es acudiendo a soluciones normativas versus soluciones racionales, racionales-instrumentales, $\mathrm{y}$, paralelamente, a teorías colectivas versus teorías individualistas del orden social, no se sabe cómo explicar la interrupción de la circularidad. 


\section{RIS}

Utilizar el esquema de la multidimensionalidad, tal y como hace J. Alexander (1990), puede resultar útil. Sin embargo, la multimensionalidad no resuelve el problema de las indeterminaciones según la perspectiva del relativismo cultural (acerca del origen y de la consistencia de los value standards que son utilizados para interrumpir la circularidad). Según Alexander, las instituciones sociales son lo que la cultura produce a través de interacciones reiteradas, es decir, a través de una multitud de operaciones repetidas y, eventualmente, re-aplicadas a sí mismas.

Quien ha rechazado este tipo de planteamiento relativista ha buscado leyes estructurales. Un buen ejemplo lo encontramos en la sociología del siglo XIX. Sin embargo, la sociedad moderna, y posteriormente contemporánea, se ha encargado de desmentirlas.

¿Dónde está el fundamento de la interrupción de la circularidad? ¿Quizá en la estructura de una supuesta realidad a priori? Sociológicamente, también esta respuesta es impracticable: una institución o relación social no es tal porque se apoye en una estructura (o en una representación simbólica) a priori. La respuesta da la impresión de ser sencilla y compleja al mismo tiempo: se fundamenta en las exigencias de la misma relación en cuanto que es activada por los sujetos que la establecen. Una relación de pareja no es la de un empresario y un obrero, o la de un médico y su paciente. Al dar una respuesta a estas exigencias, la indeterminación es limitada y la regresión al infinito se enfrenta ante unos límites: la circularidad es interrumpida por la misma relación, ya que se capta por lo que es, como aquella relación particular y no como algo diferente. Es decir, cuando se re-selecciona según su propia distinción-guía.

Afrontar los problemas anteriormente mencionados (colocarse en el nivel de la realidad sui generis de la relación social y definir el objeto en términos relacionales) comporta actualmente un cambio epistemológico al que corresponden un paradigma y una pragmática.

\section{Epistemología relacional}

La presuposición más general del pensamiento sociológico podría ser la siguiente: al principio está la relación. Esta presuposición debe ser entendida en sentido realista y no relativista ${ }^{6}$. El proceso social, con todas sus características,

\footnotetext{
" Como dice J. Pieper desde el punto de vista filosófico: "es propio de la naturaleza de la realidad el hecho de ser un posible objeto de conocimiento humano. No hay una separación total entre la realidad objetiva y el intelecto humano; cuando miramos el mundo de las cosas, ya existe antes, y precedentemente, un contacto" (Pieper, 1981: 160). Sin embargo, al hablar de contacto en vez de relación, Pieper no nos ofrece una visión propiamente relacional.
} 
procede por, con y a través de relaciones. Esto se puede afirmar tanto de la realidad social (fenomenológica), como de la teoría (observación y reflexión sobre ella). El hacerse de la realidad social y del pensamiento es relacional. Camina desde las dimensiones teóricas a los hechos empíricos y viceversa, en un continuo proceso de reflexividad entre distintas fases, también metodológicas, intermedias, siempre relativamente autónomas.

Trasladar la relación al nivel de presuposición general primera, en el ambiente metafísico del conocimiento, no implica asumir la absoluta contingencia del mundo social. Tampoco implica la aceptación de una ontología que niegue al sujeto. Al contrario, significa asumir que la relación tiene una raíz $(o$, si se prefiere, su referencia) no contingente, mientras se despliega en la contingencia. Obviamente, esa raíz o referencia está más allá de la sociedad dada y de la concreta fenomenología social.

Por tanto, se puede afirmar, por ejemplo, que las formas primarias de vida social, en cuanto relación social, están más allá de la sociedad (en el sentido de que la exceden), que van más allá porque no son mera contingencia (por ejemplo, de tipo comunicativo). Su carácter de relacionalidad plena, según la propia distinción-guía ${ }^{7}$, es lo que hace que la familia esté más allá de la sociedad, y no que, como sostiene Luhmann, tenga empíricamente en la actualidad la máxima densidad comunicativa que podemos encontrar entre todas las formas interactivas.

Desde el punto de vista sociológico, sólo la relación es necesaria en sí misma. Sin embargo, en su desplegarse refleja la efectiva contingencia del mundo social, que es "así", pero podría ser "diferente". Podría, pero no lo es: si es así es porque la relación, necesaria en sí misma, también hace que sea necesaria la exigencia de las determinaciones (las particularidades históricas), que, en sí mismas y en nuestro sistema de referencia, son contingentes.

\footnotetext{
${ }^{7}$ La siguiente afirmación de T. Huston y E. Robins (1982: 923) nos ayudará a comprender el concepto de relacionalidad plena: "Las razones por las que las relaciones funcionan como funcionan, no se pueden comprender separadamente de un contexto ecológico, un contexto que tiene componentes históricos, económicos, culturales y fisicos. Tampoco se pueden ignorar las características psicológicas y biológicas de los participantes...”. Es obvio que la investigación, tanto teórica como empirica, selecciona para los análisis especificos. Sin embargo, hay que tener presentes las reducciones de la realidad. Por ello, siempre se debería tener en cuenta que "cuanto más abstracta es la premisa, es más probable que sea auto-válida" (Bateson, 1996: 415-416). Una afirmación presentada con gran honestidad por parte del gran antropólogo americano, y que Luhmann ha aplicado al pie de la letra a su teoría. En mi opinión, el término pleno, respecto al análisis de la relación social, comparte algo con el sentido de la thick description de la que habla Geertz (1995). Dicho en otros términos, es la pluralidad de los niveles del discurso, la multidimensionalidad de los significados y su no agotamiento.
} 


\section{Paradigma relacional}

En este planteamiento, la sociedad no es concebida según los paradigmas todo/parte, sistema/ambiente o autopoiésis, sino según el paradigma de redes. La sociedad es entendida como red de relaciones.

Muy importante es comprender la relación entre el concepto de red y el concepto de sistema. El primero es más amplio que el segundo y no viceversa. Los sistemas son como una especie de condensación de las redes, en el sentido de que las redes conducen (son conductoras de) más realidad de la que podemos ver en términos de redes comunicativas, con nudos, densidades, funcionalidad, conexión y otras características sistémicas.

Es necesario replantear en términos relacionales la actual división entre análisis estructurales y análisis culturales o comunicativos de las redes. Se trata de diferenciaciones y de separaciones que, aunque estén presentes en ciertos fenómenos empíricos, tienen que ser reconsideradas a la luz de un concepto más amplio, pero, al mismo tiempo, más diferenciado y articulado de relacionalidad. Los círculos intersecantes de Simmel han representado una primera formulación. Sin embargo, en la actualidad, el fenómeno red ha desarrollado paradigmas de análisis mucho más sofisticados, hecho este en buena medida ligado a la diferenciación de la relación social en la sociedad. Si verdaderamente se quiere comprender la sociedad presente y futura, es preciso que los paradigmas elaborados por la sociología no sean puramente formales, estructuralistas o comunicacionales. Los paradigmas ambivalentes, dualistas, de oposición o de complementariedad, tienen que ser re-formulados según una lógica de redes.

\section{Pragmática relacional}

Según el análisis de redes, las implicaciones operativas de la sociología relacional se pueden concebir y estructurar utilizando perspectivas laxamente denominadas como intervención de redes. La idea-base es que la operatividad de una sociología que tiene el objetivo de servir de soporte a acciones prácticas (por ejemplo de política social y de servicio social), debe tener muy presente lo siguiente:

a) Que no existen sujetos y objetos aislados, sino complejas tramas relacionales en las que los sujetos y objetos se definen relacionalmente (que no significa de manera relativista, como si todo se pudiera leer y modificar según el gusto y el caso; el problema de la relatividad se resuelve especificando las relaciones entre los diferentes sistemas de referencia). En el caso del análisis sistemático significa concretar las variables del estado del sistema no trivial que se analiza.

b) Que cuando se interviene en un sujeto u objeto es necesario actuar sobre la trama relacional en la que están insertados, es decir, considerando los otros sujetos y objetos presentes, y los efectos de red que pueden producir las acciones. 
c) Que a ello hay que añadir la relacionalidad que existe entre quien observa y quien es observado, entre quien actúa y quien es actuado. Dicha relacionalidad tiene una connotación de círculo hermenéutico, pero sin ser indeterminado ad infinitum.

Obviamente, existen grados variables desde los que esto se puede considerar, conocer (en particular medir) y poner en práctica. Lo más importante es no legitimar reducciones selectivas a-priori o de tipo reduccionista.

Para muchos autores, el conocimiento finalizado de la acción sigue siendo una forma de observar (estudiar) las relaciones entre actores o entre hechos (por ejemplo, sociales), o entre variables (la acción, el poder, el dinero, las clases, etc.), más que una manera de observar (estudiar) los fenómenos (por ejemplo sociales) como relaciones o, aún mejor, como relaciones de relaciones. Cuando se acepta este punto de vista, el conocimiento suele incurrir en el relativismo, llegándose a la auto-destrucción del análisis de las relaciones (por ejemplo, sociales). Incluso se puede decir que, cuando la sociología ha elaborado un pensamiento relacional, éste ha tenido un carácter idealista o positivista. Generalmente no ha hecho acto de presencia un realismo de tintes críticos y relacionales. Este último asume como objetivo la comprensión-explicación no ingenua, ni reificante, ni subjetiva del mundo social como mundo que tiene una objetividad propia, construido hic et nunc y meta-existente (en el sentido de ir más allá de lo socialmente perceptible y/o percibido).

Sólo desde un mayor conocimiento de lo que la sociología construye se podrá contemplar lo que ésta debe pre-suponer y meta-suponer. En cualquier caso, saber que su objeto está socialmente construido no nos conduce a afirmar que sólo sea un producto social (por el hecho de ser producto de las relaciones sociales). De esta forma incurriríamos en un sociologismo injustificable. Para una capacidad reflexiva de este tipo, de auto-observación, es necesaria una adecuada epistemología relacional.

En las ciencias sociales, el sujeto de la acción no es observable, comprensible y explicable en sí y por sí. Su observación, comprensión y explicación sólo puede tener lugar a través de las relaciones sociales (en ellas, con ellas y por ellas). Ir más allá del carácter post-moderno implica una lectura atenta y plena, o sea multidimensional y suprafuncional (relacional), de las relaciones sociales. En ellas, el sujeto es, o puede ser recuperado, como fuente normativa de la relación, sabiendo que la acción es normativa en cuanto que implica interpretaciones (decir que la acción es normativa significa decir que necesariamente implica una lectura de los significados, y en este sentido es hermenéutica).

Lo que nos interesa conocer son los hechos sociales en cuanto hechos reales. Sin embargo, sólo podemos conocerlos en relación y a través de relaciones:

- La relación es la clave para entrar en la realidad social y para salir de ella.

- La relación no anula los términos que conecta, más bien los subraya, los explora y los expresa. 
- La relación no es mera abstración (forma o comunicación), sino un concreto.

- Este conjunto (pensamiento y realidad) relacional sólo es dicotómico (ambivalente, dual, etc.) en situaciones extremas: normalmente tiene una estructura de red, conecta, crea interdependencias, lo que conlleva tensiones y conflictos.

- Las normas (reglas) son una forma necesaria e inevitable de regular normativamente, o sea, bajo condiciones no extremas, la contingencia de situaciones que, en lo social, no están determinadas a-priori.

Brevemente, la relacionalidad, no la dualidad ni la ambivalencia, es el "juego sobre/de los juegos". Sin embargo, la relación no es un mero juego. De ella no podemos decir lo que Wittgenstein decía del juego lingüistico: "Algo imprevisible... quiero decir: no tiene fundamento, no es razonable (o irrazonable). Está allí, como nuestra vida...". Que las relaciones sociales sigan reglas vagas, desenfocadas o ambiguas, lo experimentamos cada día, así como su tendencia a polarizarse (por ejemplo en códigos binarios de tipo interno/externo o simétrico/asimétrico, que es la manera más fácil de simplificar la realidad). Pero las relaciones sociales no pueden ser estructuralmente activadas de manera incierta, ambigua o dicotómica: el objetivo de las normas es superar las ambiguedades y dicotomías que continuamente generan. La ambivalencia puede ser una característica de la condición humana, y de hecho lo es, pero no puede ser una norma que estructuralmente deba ser activada como tal. Puede serlo como estrategia, como contingencia, como defensa, pero no como norma culturalmente establecida durante largos períodos de tiempo y para la globalidad de la sociedad.

\section{EL PARADIGMA DE REDES: RELACIONAL Y NO SISTÉMICO}

Teniendo como telón de fondo la historia de los paradigmas que la sociología ha considerado a la hora de interpretar la sociedad, Luhmann habla de tres grandes paradigmas de tipo sistémico (Luhmann, 1983: 333-347):

- El paradigma parte/todo, basado en la analogía orgánica de la relación entre el cuerpo y sus órganos. Nos encontramos ante un paradigma que posee un larga tradición histórica, siendo H. Spencer el teórico más importante de la primera modernidad.

- El paradigma sistema/ambiente, desarrollado por los primeros teóricos del sistema social como relación entre roles institucionalizados y todo lo que no está institucionalizado (Parsons, 1984).

- El paradigma de la autopoiésis, para el que los sistemas sólo se constituyen a través de sus propias estructuras y operaciones. Este ha sido elaborado por el propio N. Luhmann a partir de las aportaciones procedentes de la biología y las 
ciencias cognitivas, en concreto de Maturana y Varela.

No son éstas las páginas para analizar la evolución de la teoría de sistemas y, en concreto, la posibilidad de sustituir un paradigma por otro. Tan sólo decir que, incluso el último paradigma -el auto-poiético-, si se entiende como alternativa radical, es tan problemático como el resto. El interrogante que debemos abordar en esta ocasión es el siguiente: ¿es cierto que el paradigma parte/todo está completamente superado?, y si lo está, ¿en qué sentido? La conclusión que puede extraerse de la reflexión que va desde Tönnies hasta Luhmann, es que la sustancia de la sociedad es la de ser relacionalidad. En consecuencia, un paradigma adecuado a la complejidad, si ya no es aquél que conecta la parte con el todo de forma organicista, al menos debe responder adecuadamente y según modalidades no orgánicas al problema de las relaciones entre las partes y el todo que ellas componen. Queda por ver si, en qué sentido y forma, el resto de paradigmas sistémicos existentes o posibles satisfacen esta condición de adecuación.

Mi tesis es que ni el paradigma sistema/ambiente, ni el autopoiético satisfacen la condición de conformidad relacional. El primero porque es una teoría de la diferenciación local: cada sistema se construye a partir de la identidad de la diferencia sistema/ambiente en los límites sensibles a las distinciones. El segundo porque es una teoría de los mecanismos internos de los sistemas. Por tanto, la cuestión a la que se llega es la siguiente: ¿existe un paradigma que tenga presentes las distinciones sistema/ambiente y la lógica autopoiética sin perder la relacionalidad del paradigma parte/todo? Mi propuesta es explorar esta posibilidad utilizando el concepto y el paradigma de redes. La primera cuestión que se plantea es: las redes sociales, con cuya imagen comprendemos la sociedad, ¿son sistemas sociales?

Hay quien defiende una respuesta afirmativa. En este caso, nos encontramos ante una concepción estructuralista (Blau, 1982; Blau y Schwartz, 1985) o neo-funcionalista. A quien no le satisface ninguna de las dos apela a una teoría de los sistemas abiertos que recurra a un planteamiento fenomenológico que aluda a la intersubjetividad y a la empatía ${ }^{8}$. Sin embargo, es necesario ponerse

\footnotetext{
${ }^{8}$ Por ejemplo, Ardigó (1988) habla de "sistemas abiertos de tipo empático". Sin embargo, desde la perspectiva defendida en estas páginas, hay que buscar la apertura de los sistemas en las características relacionales de los mismos sistemas y no en aspectos antropomórficos (como la empatía). La apertura de los sistemas sociales se apoya en la característica intrínseca a la sociedad que, en cuanto a relación, es red, y, por tanto, un sistema abierto (un sistema es abierto si está sujeto a la comunicación y a los vínculos externos) (Hewitt, 1984). Si el sujeto humano progresivamente se ubica en una posición externa respecto a la relación social (a la sociedad), además de estar en su interior, la red relacional se caracteriza por ser más auto-poiética. Este también es el germen del carácter emergente de la sociedad (relación social), que depende del aumento de la diferenciación en el tiempo entre interior y exterior.
} 


\section{R I S}

de acuerdo. La metáfora de los sistemas abiertos puede ser útil para subrayar los límites y los reduccionismos de la metáfora de los sistemas cerrados de tipo auto-referencial y auto-reproductivo pero no es una solución aceptable si se confronta adecuadamente con el carácter reticular de la sociedad. Si por sistema social se entiende, como hace la mayoría, un conjunto de roles ocupados y/o desempeñados por actores que interactúan a través de comportamientos, acciones y actividades de naturaleza específica (económica, política, educativa, religiosa, etc.) en el marco de normas reguladoras y de otros tipos de vínculos que limitan la variedad de los actos permitidos a cada sujeto en relación con los demás, el resultado es el siguiente: la relación social entre dos actores (individuales o colectivos) A y B sólo se concibe de forma reductiva como sistema y/o parte de un sistema en un ambiente.

El concepto de red transciende al de sistema. Como dicen Laumann y Marsden (1983:156) "no existe ningún sentido por el que las redes sociales tengan que corresponder naturalmente a sistemas sociales". Ciertamente, como plantean estos autores, no hay ninguna correspondencia si se adopta una definición de sistema social como pluralidad de actores que interactúan a partir de un sistema simbólico común. Pero, al adoptar una definición más estructural, es evidente que vínculos (regulaciones, normas) e interdependencias sólo son algunas de las dimensiones de la producción y reproducción de las relaciones típicas de las redes sociales. Dicho en otros términos, el concepto social de red incluye al de sistema, sin poder reducirlo a sistema: desde una óptica de redes, el sistema social es (i) una dimensión analítica de la red que (ii) pone de manifiesto las interdependencias y (iii) estabiliza - a través de nudos de unión/separación - los mecanismos retroactivos y los circuitos mediante los que se expresa la fenomenología de lo social. Sin embargo, la red también es el conductor, el lugar, la forma en que otros aspectos y dimensiones de lo social cobran vida y se expresan. La sociedad se presenta como una mezcla de formal e informal, que requiere un nuevo paradigma de observación.

La insatisfacción hace acto de presencia ante el hecho de que el concepto de sistema social sólo comprende algunos aspectos (llamados funcionales). Algunos autores tratan de puntualizar y diferenciar reflexivamente el concepto de sistema para comprender el aspecto informal, no funcional, de interdependencia comunicativa (comunitario, de mundo vital, etc). De esta forma, se plantea un sistema abierto cuyos rasgos son ser morfogénico (antes que mecánico, orgánico, morfoestático), selectivo, auto-directivo y auto-regulado, que opera según un código simbólico de tipo cibernético de orden superior en un ambiente (Buckley, 1982: 164-179). El resultado es el siguiente: los aspectos no formales necesariamente se asumen bajo la dimensión de sistema. Aunque este último pueda ser más flexible, con límites contingentes, el código sistémico sigue dependiendo de una lectura muy mecanicista (o sea, cibernética) de lo social. Por tanto, los contenidos no sistémicos de las relaciones sociales no son tratados 
según su propio sentido, sino reducidos al código sistémico o trasladados, por diferenciación, a otro dominio necesariamente marginal (irracional, mágico, místico, metafísico, etc.).

Por otro lado, queda claro que las redes sociales no son espontaneidad e intersubjetividad contingente: éstas se identifican con unos recorridos en los que la persona es, al mismo tiempo, libre y no soberana, es decir, no es dueña de lo que es libre de hacer. Un estudio de las redes sociales primarias (o informales) de la vida cotidiana representa un punto de observación ilustrativo sobre la relación social no como sistema, ni como mundo vital (intencional en sentido humano) de uno y otro.

A través de este itinerario conceptual que abarca toda la reflexión sociológica contemporánea, es posible introducir un cuarto paradigma, a saber: el paradigma de redes.

Este paradigma reconoce, en primer lugar, que ha venido a menos̉ la coherencia sistémico-normativa de los dos primeros paradigmas sistémicos - todo/parte y sistema/ambiente - y que la sociedad contemporánea está intrínsecamente caracterizada por la distancia y la fragmentación de las relaciones sociales. Asimismo, rechaza, en segundo lugar, el modelo auto-poiético como modelo total, aunque admite la validez del concepto y la necesidad de incluir la auto-referencialidad en la observación de la fenomenología social. En tercer lugar, reconoce que los actores sociales no se mueven, ni pueden moverse libremente, sino que están ubicados en senderos elaborados culturalmente. Finalmente, interpreta el nacimiento de una nueva normatividad para la que se debe elaborar una teoría de los sistemas creadores de reglas sociales, basada en una lógica de red, que al mismo tiempo es estratégica (cognitivoinstrumental), comunicativa (expresiva, dialógica) y normativo-valorativa (generalización de valores).

Por tanto, no resulta arriesgado decir que el concepto de red muestra su capacidad para construir un meta-código simbólico para el concepto de sistema. Posteriormente, esto último debe ser generalizado y diferenciado (reflexivamente). Sólo así el análisis puede comprender las redes sociales como realidades formales e informales conjuntamente.

\section{ANÁLISIS SISTÉMICO-FUNCIONAL Y ANÁLISIS RELACIONAL}

Si de verdad se quiere entrar en un pensamiento relacional no reductivo, es necesario adoptar una posición crítica respecto al pensamiento funcional, en concreto de la versión que va desde Durkheim a Luhmann.

El análisis sistémico funcional ha sido el background, el leit-motiv, la infraestructura paradigmática, tanto en sociología, como en el resto de las ciencias sociales, del pensamiento teórico y de la investigación empírica. El 
cambio relacional que describimos al inicio de estas páginas, se ha desarrollado, en buena medida, a partir del funcionalismo. Merece la pena recordar brevemente cuáles han sido sus diversas etapas.

\section{Primer funcionalismo (Durkheim)}

La relacionalidad en sentido moderno hace su entrada en las ciencias sociales de la mano de Durkheim y su específico funcionalismo. Este consiste en definir los entes sociales como relación, con las funciones que realizan por y en la sociedad, y no según su naturaleza o sustancia. Desde sus orígenes, esta concepción de la relacionalidad ha estado marcada por algunas elecciones particulares de tipo positivista. Con sus reglas del método sociológico Durkheim realiza una serie de operaciones fundamentales.

En primer lugar, sustituye y opone la función al objetivo. El finalismo tenía que ser rechazado por la sociología: "preferimos utilizar la palabra "función" en lugar de "objetivo" o "fin"... Si existe correspondencia entre el hecho considerado y las necesidades generales del organismo social [es independiente] de que haya sido o no intencional" (Durkheim, 1964). La analogía organicista tenía que asegurar la objetividad (positiva) del análisis. Como más tarde dirá Merton, "la función social alude a las consecuencias objetivas observables, y no a disposiciones subjetivas (fines, motivos, objetivos)" (Merton, 1972: 129).

En segundo lugar, y a partir de estos fundamentos, el análisis sociológico habría tenido, según Durkheim, que explicar los fenómenos a través de dos reglas: relacionar las partes de la sociedad al todo, y relacionar desde las funciones cada una de las partes entre sí.

Para Davis, estos postulados "simplemente describen lo que hace toda ciencia" (Davis, 1959: 758). En su opinión, fuera del análisis sistémico funcional no existen más que errores. El no-funcionalismo siempre deriva en un reduccionismo, como el psicológico - que reduce lo social a estados de la conciencia individual - o el biológico - que reduce la explicación de lo social a la herencia genética-, o bien a un determinismo como el económico o el tecnológico. Asimismo, siguiendo a Davis, el no-funcionalismo conduce a un empirismo grosero, es decir, la mera manipulación no-teórica de los datos, mientras que el análisis sistémico funcional implica un modelo interpretativo, y no simplemente relaciones estadísticas o datos históricos. Como recuerda Davis, la fisiología ha sido y es el modelo analítico de referencia para todos los autores funcionalistas (en concreto, Radcliffe-Brown, Malinowski, Firth y Merton).

Aparentemente, el intento de trasladar el lenguaje científico a lenguaje funcional de sentido común pragmático es muy simple: "Hablar de la función de una institución para la sociedad o para otra institución en esa sociedad es un modo de preguntarse lo que la institución hace dentro del sistema para el que 
es relevante" . El funcionalismo, en esta primera versión, es la descripción y explicación de los fenómenos desde la perspectiva de un sistema de razonamiento que presumiblemente está relacionado con el correspondiente sistema en la naturaleza: tan sólo que, en el caso de la sociología, el objeto de estudio no es el mismo que en las ciencias naturales, sino la sociedad (Davis, 1959: 759).

Ahora bien, ¿cuál es el fin de la comprensión y dónde está la interpretación? Desde sus inicios, el análisis sistémico-funcional presenta numerosas dificultades: no solamente decide eliminar al sujeto humano (con sus motivaciones y experiencias interiores para la acción), sino que también trata a la cultura como algo natural. Por tanto, es inevitable que la sociedad aparezca marcada por los tintes del mecanicismo. Si se aceptan las operaciones anteriormente mencionadas, la relación social se reduce a una mera estructura ${ }^{10}$ en la que la cultura aparece como una gama de opciones de elección vinculada. Estamos ante ambigüedades a las que se puede aplicar el calificativo de fuertes, que el primer funcionalismo no sabe cómo resolver. La sociedad se configura como un organismo cultural, pero se estudia como un organismo natural en evolución. Este tipo de presuposición general nunca se rechazará o negará, tampoco por Luhmann.

\section{Segundo funcionalismo (Parsons)}

Con Parsons, el funcionalismo sigue en el vacío estructural de Durkheim. Sin embargo, en cuanto que el sociólogo de Harvard pretende unir el actuar intencional de Weber y los factores no-racionales de Pareto (el famoso supuesto de convergencia entre Durkheim, Weber y Pareto sobre la teoría de la acción), la teoría debe abandonar la pretensión de llegar a formular leyes científicas exactas.

El funcionalismo de Parsons, al menos en su primera etapa, se caracteriza por el intento de no perder al sujeto humano como sujeto de la acción y otorgar a la cultura no sólo mayores grados de libertad, sino también el significado de latencia (la referencia a los valores últimos inexpresables). Con ello da la impresión de que la relación se puede re-definir en términos no reduccionistas. Sin embargo, Parsons nunca dará este paso. Las ambigüedades siempre estarán presentes. Mantener al sujeto y a la cultura en la teoría sociológica siempre será más díficil, por no decir imposible, para la tradición funcionalista.

\footnotetext{
${ }^{9}$ El ejemplo es el siguiente: "si cada vez que se establece una relación se debe decir la función de esto y aquello, y de hacer esto y aquello, la circunlocución se convierte en un lastre ¿Por qué no decir simplemente que el corazón bombea la sangre a través del sistema?" (Davis, 1959: 772).

${ }^{10}$ Así es como ha estado tratada en la obra de R. Merton.
} 
Con la adopción de la perspectiva sistémica, su redefinición en clave biológica $\mathrm{y}$, especialmente, cibernética, el funcionalismo llega a una relacionalidad cada vez más estructuralista y relacionista. El sistema sustituye al sujeto, y la cultura se ve reducida a un subsistema.

Respecto al funcionalismo ingenuo y primitivo del siglo XIX, con Parsons se lleva a cabo un cambio relacional: del paradigma todo/partes se pasa al paradigma sistema/ambiente. También en este caso la acción social es definida como relación. Sin embargo, el corazón de la relación es el sistema. Este, como sistema social, permanece enclavado en una metáfora espacial (en relación al ambiente): una carga que la teoría nunca logrará justificar.

Integración social e integración sistémica ya no estarán comprendidas en la teoría; al contrario, se opondrán la una a la otra como dos teorías incompatibles, como si fuera una el ambiente de la otra. De este modo, la relación social se divide en unas dimensiones intersubjetivas (integración social) y funcionales (integración sistémica) que se limitan y rechazan entre sí. Los funcionalismos clásicos no consiguen resolver estas ambigüedades.

\section{Tercer funcionalismo (Luhmann)}

Luhmann ha elegido el camino más consecuente respecto a los puntos de llegada del funcionalismo clásico (parsonsiano) y sus ambivalencias no resueltas. En su perspectiva están presentes las conclusiones más radicales que marcan al funcionalismo desde sus inicios. El eje de la construcción teórica funcionalista (el concepto de sistema) aparece como el axioma fundamental que redefine el resto de los conceptos de la teoría. La distinción sistema/ambiente, introducida en la teoría sociológica por Parsons, se convierte, con Luhmann, en la diferencia-guía de la teoría como unidad de la diferencia entre identidad y diferencia. Aunque implícito desde el principio, el resultado es el tránsito al nuevo paradigma funcionalista: el paradigma auto-referencial auto-poiético.

Como ya había estado presente en el tránsito de Durkheim a Parsons, conviene apuntar que, en Luhmann, cierto concepto de relación está en los fundamentos del cambio. Ahora "la teoría tiene necesidad de conceptos formales ubicados en el nivel de la creación de relaciones entre relaciones" (Luhmann, 1998: 74). Desafortunadamente, Luhmann radicaliza una concepción formalista de las relaciones sociales, tratándolas como relaciones lógicas. De este modo, la relación puede y debe aludir en primera instancia a sí misma.

El tránsito del paradigma sistema/ambiente al nuevo paradigma autoreferencial está marcado por una concepción de la relación como causa sui:

"En el ámbito de la teoría sistema/ambiente todavía era posible una configuración teórica relativamente simple, y desde luego esta teoría pudo ser interpretada como mera ampliación de las relaciones causales. Según esta concepción, en cada relación causal 
hay que tener en cuenta tanto los factores externos como los factores internos; sistema y ambiente se encuentran en una especie de co-producción. La teoría de los sistemas auto-referenciales se aleja de este modelo causal. Considera la causalidad (como también la deducción lógica y cualquier tipo de asimetría) como si fuera una organización de auto-referencia, y explica la diferencia entre sistema y ambiente en cuanto que sólo los sistemas auto-referenciales consiguen ordenar causalidades distribuyéndolas entre sistema y ambiente" (Luhmann, 1998:74-75).

La relacionalidad se ve sometida a una redefinición radical que podemos sintetizar así:

1) Lo constitutivo del mundo (material, psíquico, social) tiene que ser observado y explicado a través de una utilización relacional de la relación en sentido lógico; no se puede evitar utilizar la relación, ella es la trama de todo; en los sistemas basados en el sentido, la relación equivale al sentido; mejor dicho, el sentido es la relación misma en sentido lógico.

2) La teoría debe elaborar conceptos que tengan capacidad relacional; por ejemplo, el concepto de complejidad debe construirse de forma compleja interiormente, y forma compleja significa prever un numero indefinido de relaciones, además de otros elementos ${ }^{11}$.

3) Al mismo tiempo, la relación "se configura como reducción de la complejidad, es decir, tiene que ser entendida como fenómeno emergente" (Luhmann, 1998: 210). Dicho en otros términos, es la relación (en sentido lógico) la que reduce y amplia la complejidad.

4) La relación social ya no es la expresión activada por uno o más sujetos; ya no es posible hablar de relación entre individuos (y esto porque si vienen a menos los individuos, la relación desaparece); se elimina la idea de una acción recíprocamente anticipadora (finalizada); los individuos-personas ya no están seguros de comunicar de forma comprensible, porque cada comunicación se refleja en el espejo de subjetividades auto-referenciales progresivamente fluctuantes. Aparece el problema de concebir cuál puede ser la unidad de una relación que conecte una pluralidad de sistemas auto-referenciales. Las relaciones sociales sufren una temporalización radical y se hacen circulares. Las secuencias conectivas que se establecen son cada vez menos previsibles.

" Dice Luhmann: "Cada realidad compleja se basa en una selección de las relaciones entre los elementos que tal realidad utiliza para construirse y mantenerse. La selección ubica y califica los elementos, aunque éstos podrían establecer relaciones diferentes" (Luhmann, 1998: 95). "Se debería hablar de reducción de la complejidad cada vez que la estructura relacional de un fenómeno complejo es reconstruida por un segundo fenómeno caracterizado por un número menor de relaciones. Sólo la complejidad puede reducir la complejidad" (Luhmann, 1998: 97). 
RIS

El funcionalismo da paso a una contingencia invasora, tan sólo mitigada por la necesidad pragmática de estructuración (temporal y secuencial) del sistema.

En última instancia, aparece como un relacionamiento sistémico-funcional de relaciones funcionales. No resulta arriesgdo decir que, a partir de estos momentos, el funcionalismo se apoya en arenas movedizas.

Ciertamente, en las ciencias naturales, el análisis sistémico-funcional ha mostrado mejores prestaciones que otros métodos. Como dice A. Gehlen: "La ciencia moderna de la naturaleza prueba a fondo todos los procesos presentes en un determinado campo; por tanto, actúa de forma sistémica y de manera funcional" (1983: 257). Sin embargo, en el campo de las ciencias sociales, las cosas son diferentes. Aparentemente, el funcionalismo parece fuerte. Basta con contemplar lo hecho por la Escuela de Frankfurt. Al margen de las críticas a Parsons por haber minusvalorado el lebenswelt, Habermas ha terminado por revalorar buena parte de la teoría parsonsiana. El resultado ha sido poner de manifiesto lo siguiente: los que están en contra de cualquier regreso al funcionalismo poseen una teoría débil de la cultura y del sujeto de la acción social.

Todo esto confirma que, para las ciencias sociales modernas, el análisis sistémico-funcional no es un planteamiento o un método entre otros, sino que representa la trama del discurso científico. La superioridad de la teoría de Luhmann respecto a la de Habermas está en que Luhmann no se ha posicionado contra el análisis sistémico-funcional, sino dentro y en total acuerdo con él, mientras que Habermas ha intentado reconducirlo, o por lo menos hacerlo compatible, con una perspectiva normativa (los ideales de modernidad).

Como mentalidad y como código simbólico, el análisis sistémico-funcional no sólo ha representado la progresiva erosión de las tradiciones culturales en Occidente y Oriente, incluidas las tradiciones modernas (por ejemplo, liberales y socialistas), sino que ha demostrado que sabe regenerarse continuamente a través de formulaciones cada vez más sofisticadas. Hay quien piensa que las tradiciones culturales son capaces de recuperarse y tomarse la revancha. También están los que opinan que ciertos sistemas comunistas, quizás en países como China o en el Tercer Mundo, son capaces de resistir el asalto del capitalismo y de renovarse a partir de la emancipación socialista. Los que no comparten este tipo de esperanzas porque las consideran simples ilusiones, se plantean el problema de comprender por qué y cómo el funcionalismo, a pesar de sus límites, sigue siendo, al menos aparentemente, el ganador.

Desde Durkheim a Parsons, desde Alexander a Luhmann, el funcionalismo adopta formas nuevas y diferentes, demostrando siempre una capacidad de validez impresionante. Hace veinte años, Gouldner escribió que el funcionalismo debía considerarse muerto. No era una opinión aislada. Sin embargo, no ha sido así; ¿por qué? ¿cuál es su fuerza? En primer lugar, habría que decir que el funcionalismo está desvinculado de juicios de valor. Teóricamente se basa en un quantum (variable) de relativismo epistemológico y cultural que, en el plano 
moral, conlleva cierto grado (variable) de relativismo. Esta es su primera fuerza: poder ser compatible con diversas posiciones lo hace accesible a diferentes planteamientos. También puede incluir todos los conceptos e instrumentos que no implican una toma de posición. En segundo lugar, es un método que utiliza categorías lógicas con elevado poder de abstracción. El concepto de función, análogo al de las matemáticas, permite juegos lógicos y mentales ilimitados. Está claro que el análisis sistémico-funcional tiene la misma función en sociología que las matemáticas en la economía. No es posible estar sin él. Sin embargo, las matemáticas no son todo, ni representan una forma de comprender y explicar la economía; tan sólo decir que facilitan los cálculos y permiten la previsión de ciertos aspectos. Igual ocurre con el análisis sistémico-funcional para las ciencias sociales.

Utilizar las categorías luhmannianas implica decir que la distinción-guía del análisis sistémico-funcional (funciona/no funciona) ${ }^{12}$ no tiene rival. Ahöra bien, el riesgo es la renuncia al interrogante ¿qué significa funciona o no funciona? Indubablemente, no se puede negar la dificultad de competir con un paradigma que se mide por la eficacia de sus construcciones indicativas. Pero nos encontramos ante un punto muy delicado: ¿cómo definimos la eficacia? Luhmann es taxativo: como "selección de estructuras suceptibles de afirmarse". Más concretamente: el funcionalismo convence y triunfa porque es el método de la competición y de la lucha por la vida. Sin embargo, es evidente que esconde detrás de sí una ideología, aquella del achievement de Parsons. El que el achievement ya no se entienda como movilidad social, éxito económico o social, y sea sustituido por la capacidad de fitness biológico no cambia la sustancia de las cosas: tan sólo desculturaliza la ideología.

En consecuencia, el funcionalismo sería el triunfador porque da la razón al ganador. Su constitución auto-referencial es la base de su fuerza. Pero, ¿verdaderamente es tan fuerte? Aún siendo fascinante, la solución funcionalista deja abierto el problema de los límites con lo no-funcional. El problema de la interpretación, que es necesario tener presente para dar cuenta de lo no-funcional, no puede resolverse desde el análisis sistémico-funcional. Esta es la mayor dificultad del funcionalismo. Hasta ahora, ningún funcionalismo ha conseguido mostrar el sentido humano de lo que el análisis funcional deja provisionalmente al margen.

\footnotetext{
${ }_{12}$ Dicho de forma más sofisticada: "El planteamiento funcional es un planteamiento morfogenético de importancia determinante, capaz de guiar, en el proceso evolutivo, la selección de estructuras susceptibles de afirmarse" (Luhmann, 1998: 470). En la referencia bibliográfica sobre este punto, Luhmann alude explícitamente a Durkheim y a las investigaciones socioantropológicas comparativas que, en su opinión, demuestran la validez de la concepción planteada por este último.
} 
RIS

Para algunos, si se utiliza la hermenéutica, con el funcionalismo es posible un análisis de la cultura como sistema organizado de símbolos significativos. En esta línea se nos enmarca J. Alexander. Ciertamente, la lectura de la acción social como texto (Ricoeur, 1989) es una componente relacional importante para evitar la reducción de la acción a comportamiento. Sin embargo, desafortunadamente, olvida la naturaleza específica de lo social como sociedad. De esta forma, la crítica aflora con facilidad: si se toma la perspectiva hermenéutica, lo más que se puede hacer es una buena exégesis, pero no se puede dar una explicación propiamente sociológica. Esto es lo que ha hecho Luhmann: en su teoría, el funcionalismo rechaza la hermenéutica como método de análisis en cuanto que, en su opinión, apelaría a entidades mágicas (míticas) y a un trascendentalismo que se aleja del realismo científico.

Para el funcionalismo, la cultura debe leerse desde el interior de un framework que, si no es positivista, es (o debe ser) naturalista. Al final, incluso dentro del funcionalismo nos encontramos con el dilema entre explicaciones idealistas y materialistas. Por una parte, la realidad (realistas) de la que habla Luhmann es material. Se trata de un realismo sofisticado: vitalista, pero materialista. Por otra, la acentuación que Alexander hace de la cultura (siguiendo en este punto al Durkheim religioso) conlleva el riesgo de un desequilibrio hacia el idealismo.

El problema no es negar la validez del funcionalismo en el ámbito de sus reducciones. Más bien es, por un lado, demostrar como éste genera, en su proceso y a través de sus estructuras, lo que no es funcionalismo en el sistema y en el ambiente, incluso en las mismas unidades de la diferencia sistemaambiente. Por otro, cómo consigue explicarlo sin caer en el materialismo $o$ en el idealismo.

El funcionalismo traslada al no funcionalismo, como las matemáticas en economía llevan a comprender la existencia de lo que, en la acción y en el sistema económico, no es matematizable. Queda claro que el análisis sistémico-funcional no puede abordar lo no funcional ¿Cómo podría explicar Luhmann el don de la vida, el acto gratuito o el rechazo de la comunicación, la implosión del sentido, la necesidad de justicia y la utopía de muchos movimientos sociales y su dinámica? ¿Cómo es posible, tomando como referencia el funcionalismo auto-referencial, explicar la creatividad humana, la aparición de selecciones combinatorias no pensadas e improbables, la irrupción de un nuevo sentido de las cosas? ¿Tan sólo estamos ante nuevas conexiones activadas por variabilidades causales que actúan a través de mecanismos de un sentido sistemáticamente entendido?

El problema de incluir-excluir lo no funcional no puede ser asumido por el funcionalismo. Para resolver esta tarea es necesario observar el funcionamiento de las distinciones-guía funcionalistas desde un punto de vista más general. "Hay que cambiar las matemáticas". Este es el punto de vista de la sociología relacional. Para ésta: 
- Además de las dimensiones materiales, psíquicas y sociales, el sentido tiene una dimensión cultural. La dimensión temporal del sentido atraviesa y constituye estas cuatro formas del sentido como otra dimensión respecto a sus contenidos. A éstos atribuye un dinamismo propio (el tiempo cambia el sentido).

- La acción es tanto el acto intencional, como el acto emergente, obviamente de forma diferente.

- A su vez, el sistema es intencional y no intencional.

- La complejidad no es sinónimo de mera contingencia, sino la combinación de necesidad y contingencia, de estructura y acontecimiento.

- La relación social es suprafuncional.

Mediante este marco más general es posible mantener lo mejor del análisis sistémico-funcional dentro de un análisis relacional que elabora una teoría más adecuada de la sociedad. La solución de los dilemas planteados por el funcionalismo no consiste en negar la importancia del análisis sistémicofuncionalista. Mas bien está en orientarla hacia un paradigma más general. La nueva distinción-guía es la relación. En sociología, la observación distingue si un actor, acontecimiento, estructura o acción social, relaciona o no relaciona y la manera en que lo hace.

Para el primer funcionalismo es válida la ecuación $\mathrm{y}=\mathrm{f}\left(\mathrm{x}_{\mathrm{i}}\right)$, donde $\mathrm{x}_{\mathrm{i}}$ son factores variables. Para el segundo funcionalismo es válida $\mathrm{y}=\mathrm{f}\left(\mathrm{x}_{\mathrm{i}}, \mathrm{r}_{\mathrm{j}}\right)$, donde se introduce la relación entre los factores como variable. Para el tercer funcionalismo es válida $y=f\left(x_{i}, r_{j}, r_{n}, r_{j}\right)$, donde se introduce como variable el relacionamiento de las relaciones. El análisis relacional no niega los progresos científicos que estas reformulaciones paradigmáticas han conseguido. Pero plantea la necesidad de poner en lugar de $f$ la relación $\mathrm{R}$, que representa una referencia compleja y vínculos complejos no necesariamente funcionales: $y=R\left(x_{i}\right), y=R\left(x_{i}, r_{j}\right), y=R\left(x_{i}, r_{j}, r_{n}, r_{j}\right)$. En sociología, el operador relacional, $\mathrm{R}$ es una relación social cuyas funciones no pueden desconectarse del sentido total que poseen.

Decir que una entidad - a pesar de ser variable y poder ser un comportamiento, una estructura o un acontecimiento- depende de - es contingente respecto aotras variables $\left(\mathrm{x}_{\mathrm{i}}\right)$, significa analizar el operador $\mathrm{R}$ que las relaciona, de manera compleja y supra-funcional, a través de relaciones entre los elementos $\left(r_{j}\right)$ y relaciones de relaciones $\left(r_{n} r_{j}\right)$. Estas relaciones sólo se pueden considerar lógicas mediante una abstracta formalización: para los sistemas construidos a partir del sentido (de un sentido entendido como selección significativa), primariamente las relaciones son patterns culturales interpretados por los actores.

Las implicaciones de ese cambio de paradigma se pueden comprender mejor a través de una crítica del análisis neo-funcionalista luhmanniano.

1) El análisis sistémico-funcional no presenta modelos para no dar la impresión de elaborar determinaciones estructurales. Tampoco el análisis relacional utiliza modelos y determinaciones estructurales, si por esto se 
entienden determinaciones a priori. Sin embargo, mantiene que la realidad social manifiesta la exigencia de determinaciones estructurales. Por ejemplo, la estructura de la reciprocidad: ciertamente no es una estructura que determine los comportamientos y las acciones empíricas a priori, pero representa una exigencia que tiene la cualidad de la referencia de un arquetipo en el que se basa la observación y la evaluación de los fenómenos emergentes de las interacciones.

2) El método del análisis sistémico-funcionalista se basa en el concepto de información. Estamos ante un tipo de técnica teórica comparable con las matemáticas. Sin embargo, el método del análisis relacional, por su parte, se basa en el concepto de relación. Mientras que la información atribuye una forma, la relación también es conductora de contenido. El análisis relacional es una técnica teórica que, cuando trabaja con las relaciones sociales, no separa la formalización matemática de los contenidos transportados por las relaciones.

3) El análisis sistémico-funcionalista recurre a la creación de relaciones con la finalidad de captar lo existente como contingente (en el sentido de posible) y lo diverso como comparable. Cuestiona la realidad dada intentando demostrar que el problema se puede resolver de una forma $u$ otra. La relación entre problema y solución del problema no se entiende como fin en sí misma, sino que se utiliza como hilo conductor en la búsqueda de otras posibilidades, es decir, de soluciones funcionales equivalentes. En cambio, el análisis relacional utiliza la investigación de las relaciones existentes y posibles para demostrar por qué y cómo la realidad es así y no de otra forma. No intenta justificar lo existente, sino comprenderlo como realidad de hecho. El análisis cuestiona la realidad para comprender por qué el problema se ha resuelto así y no de otra forma. La relación entre problema y solución del problema es la clave de lectura, también hermenéutica, de las determinaciones que han llevado a ciertas soluciones en la realidad social, ante la presencia de otras soluciones posibles.

4) En el análisis sistémico-funcional los problemas sólo se cociben como problemas sistémicos (son tales porque es imposible afrontarlos y resolverlos aisladamente). Por este motivo, cualquier orientación sistémico-funcional contempla un contexto que no puede descomponerse, sino tan sólo ser destruido. El planteamiento sistémico-funcional es intrínsecamente holista. Por su parte, en el análisis relacional los problemas son relacionalmente co-determinados en un contexto que se puede descomponer a partir de los actores y sus relaciones. No se rechaza el planteamiento holista, pero éste se relaciona con el individualista a través del análisis de las relaciones.

5) El método sistémico-funcionalista es un método comparativo y su aplicación a la realidad sirve para que lo existente considere otras posibilidades. En definitiva, individia relaciones entre relaciones porque conecta algo con un determinado aspecto problemático, para, posteriormente, conectar con otras soluciones del problema. La explicación sistémico-funcionalista no puede ser más que la individuación y la exclusión de equivalentes funcionales. La acción 
de la orientación sistémico-funcionalista consiste en ampliar y restringir lo posible. En cambio, el método relacional es un método de referencia y conexión, en el que la comparación tan sólo es un aspecto. Las relaciones no sólo se constituyen en el marco de otras posibilidades, sino desde el horizonte de referencias relevantes y aceptables según los datos del contexto. La explicación relacional consiste en demostrar cómo los fenómenos sociales existen en cuanto se activan ciertas relaciones y no otras. La especificidad del análisis relacional está en presuponer la supra-funcionalidad de las relaciones.

6) La principal prestación teórica que prepara la utilización de los análisis funcionales consiste en construir el problema como problema sistémico. Ya no se trata de un sistema - entendido como unidad caracterizada por determinadas propiedades-a partir de cuya estabilidad se toma una decisión global. Más bien se pretende continuar o interrumpir la reproducción de elementos a través de la disposición relacional de esos mismos elementos. En este caso, la conservaciốn significa mantener el carácter cerrado y permanente de la reproducción de elementos que desaparecen en cuanto surgen. Al contrario que los análisis funcionalistas, la principal prestación teórica del análisis relacional es la definición (traducción, interpretación) relacional del fenómeno que se observa, en el marco de un contexto entendido como red de relaciones. No se presupone ningún sistema; y en consecuencia la estabilidad o inestabilidad de este último, como su cierre, es algo que resulta extrínseco al punto de vista del observador. Este último observa una red morfogenética (con grados variables) de relaciones.

7) El concepto de función es definido como directiva a confrontar. Este designa una realidad de hecho que, se supone, trasciende la mera continuidad de la reproducción auto-referencial (conservación de la estabilidad). El concepto quiere expresar algo más que la vida biológica: indica una intención comparativa, una expansión de la contingencia, una perspectiva de observación. No queda claro cómo un sistema auto-referencial puede observarse a sí mismo. Más misterioso es cómo, siendo auto-referencial, puede confrontarse con otros sistemas auto-referenciales. Sin embargo, el concepto de relación es definido como una directiva referente a la conexión. Por eso anula los problemas anteriormente mencionados.

8) La concepción de la ciencia del análisis sistémico-funcional conlleva la primacía de la referencia sistémico-funcional (es decir, a la "A" de AGIL: un objetivo puede perseguirse mediante diferentes medios, funcionalmente equivalentes, por el mero hecho de ser medios) ${ }^{13}$. El principio prioritario de

\footnotetext{
${ }^{13}$ En palabras de Luhmann: "La orientación a la función también es una forma de producción de redundancia, o sea, de seguridad. Ella hace que modos distintos de trámite de la función aparezcan como funcionalmente equivalentes y puedan ayudarse el uno al otro ofreciendo seguridad en el caso de resultados negativos" (Luhmann, 1998: 469). Aunque admita que "ninguno se siente seguro
} 


\section{RIS}

selección de datos científicos es la referencia sistémico-funcional (confrontada con otras posibilidades funcionalmente equivalentes). La dificultad de la ciencia al radicalizar el punto de vista sistémico-funcional (también en la auto-observación) no encuentra otra explicación que el recurso a inhibiciones (alternativas imposibles) y, en consecuencia, debe imputarse a dogmatismos. Sin embargo, el análisis relacional concibe la ciencia como forma compleja de saber con diversos componentes, no sólo cognitivos, sino también expresivos, simbólicos y morales. Estos poseen complejas relaciones entre sí. La dificultad de la ciencia al radicalizar el punto de vista sistémico-funcional está en que el saber no puede ser reducido a función o encontrar en la función su principio-guía. Las inhibiciones pueden tener diversas motivaciones y expresiones, incluidas las dogmáticas, pero no son siempre dogmáticas. Se puede y se debe aceptar que el sistema observado por la ciencia esté reforzado por un procedimiento de reproducción y aumento de la complejidad que es impracticable por el mismo sistema. El que esta operación pueda minar las certezas intuitivas del sistema observado (por ejemplo, el sentido común), hasta el punto de destruirlo, explica buena parte de las resistencias y de los fracasos de la ciencia tradicional. Sin embargo, para el análisis relacional, el conocimiento de sentido común no es un conjunto de meros residuos o tradiciones culturales: se trata de otras formas del saber que el análisis sistémico-funcional ignora.

9) El análisis sistémico-funcional considera el estudio de las funciones latentes y el cuestionamiento de lo existente (la redefinición en términos de contingencia de lo manifiesto) como cargas excesivas para el propio objeto. Desde su perspectiva, sólo el planteamiento conceptual sistémico permite tratarlos. Por su parte, para el análisis relacional, lo latente y la contingencia constituyen la normalidad del mundo social, en cuanto que, desde el principio, las relaciones son asumidas como supra-funcionales.

10) El análisis sistémico-funcional se auto-concibe como una simplificación del sistema observante y observado a partir de selecciones de esquemas relacionales preferenciales. Sin embargo, el análisis relacional muestra que estas simplificaciones pueden comprenderse mejor en el marco de un planteamiento relacional (más que sistémico-funcional) de las relaciones en juego. La

\footnotetext{
porque todo lo que ocurre tiene la función de reducir la complejidad", no se preocupa de observar si y cómo la seguridad también puede ser producida de otra forma. Estamos ante una extraña manera de realizar análisis sistémico-funcionalistas porque no se presta atención a los equivalentes (funcionales o no). La razón, obviamente, existe. Se basa en que, una vez anunciado que el procedimiento evolutivo de variación y selección en las referencias funcionales se hace "a ciegas", sólo A de AGIL (la existencia de opciones instrumentales, de medios, "suficientes" como variety pool y como GOD = Generator Or Diversity) puede ofrecerle seguridad.
} 
complejidad que trata el análisis relacional es diversa y mayor que la que está presente en el análisis sistémico-funcional.

11) El análisis sistémico-funcional se propone incrementar los conocimientos mediante una redefinición del mismo conocimiento. Esta desplaza la atención desde la relación sujeto/objeto al plano sistema/ambiente y, posteriormente, al eje de la auto-referencia del objeto (sistema observado) y de la auto-referencia del propio análisis (sistema observante). El motivo es bien sencillo: al elegir un problema que expresa la unidad de la diferencia entre conocimiento y objeto, el método sistémico-funcionalista deja de ser una mera elección metodológica y aspira a ser teoría del conocimiento. En este sentido, la verdad científica ya no es una correspondencia entre conocedor y conocido, sino una manera de confirmar la validez de la forma semántica en la que se presentan los resultados de la observación ${ }^{14}$. En cambio, el análisis relacional enseña que esta antigua aspiración del método sistémico-funcional de trascender el ser una elección metodológica para convertirse en teoría general del conocimiento, es una pretensión ilegítima. Los incrementos de conocimiento producidos se pueden comprender desde la epistemología relacional como especificaciones según líneas-guía muy particulares de diferenciación cognitiva. Sin embargo, en la perspectiva relacional la verdad permanece como correspondencia adecuada, relacionalmente definida, entre conocedor y conocido.

\section{EL PLANTEAMIENTO RELACIONAL MÁS ALLÁ DEL FUNCIONALISMO}

Tras este recorrido por el funcionalismo, la conclusión que se puede extraer es la siguiente: una comprensión insuficiente de la relacionalidad social termina por prejuzgar tanto a la teoría social, como a la práctica de la intervención social. Es necesario afirmar que ni pura acción (puro individuo), ni puro orden social (pura estructura). La realidad social es relacional. Pero no sólo esto. También hay que evitar asumir presuposiciones radicalmente relativistas y contingentes. Se debe mirar a la lógica de la relación social como tal. Si la relación social es

\footnotetext{
${ }^{14}$ Luhmann observa que "lo que hemos definido como análisis sistémico-funcionalista es, en el marco del sistema social, un principio de observación científica del sistema, pero no es eo ipso un principio de auto-organización de las condiciones sociales que cotidianamente se reproducen" (Luhmann, 1998: 470). Precedentemente, había aclarado que: "ese método ordena y precisa las condiciones en las que las diferencias 'hacen diferencia'. Se trata de un horizonte particular del mundo vital, instituido para objetivos especificos, que somete a determinadas condiciones el control de las diferencias, pero que está presente en cada tipo de manipulación de las informaciones, dotándolo de una forma determinada" (1998: 126). En consecuencia, en sociología, el análisis sistémico-funcionalista se concibe como una forma de producir conocimientos ya establecidos.
} 
R I S

REIISTA INTERNACIONAL DE SOCIOLOGIA

No 28. Enero - Abril. 2001

contingencia, los términos que une e incorpora y las dinámicas que expresa no son puramente contingentes. Y tal no-contingencia del mundo social no sólo está en los condicionamientos históricos y en el mundo que socialmente nos es transmitido, sino que también está en exigencias que son inmanentes y trascendentes a la acción y al orden social.

Las redes sociales están constituidas por libertad y condicionamientos estructurales: aún más, son la expresión de la relación, siempre problemática, entre libertad y determinismo.

El mayor riesgo de una sociología relacional es incurrir en la circularidad de la teoría. Como se ha visto con anterioridad, el neo-funcionalismo no puede evitarlo. El resultado es, en algunos casos, la incerteza y la posible confusión en las relaciones entre objeto y sujeto, entre agente humano y estructura, entre libertad y vínculos, etc.

Si se fomenta una epistemología de la pura adaptación a una supuesta evolución social, tal y como hace el funcionalismo, se corre el riesgo de caer en una concepción totalmente circular de las relaciones sociales. Por una parte, tal concepción se presenta compleja en cuanto que no vienen individualizados los puntos en los que se puede destruir o cerrar; por otra, es simplista ya que renuncia a indagar en por qué la relación tiene una estructura no casual. Ciertamente, tal concepción se caracteriza por la apertura a una realidad no dada, o no estipulada, en sus límites precedentes. Sin embargo, no se enfrenta totalmente con los efectos y los límites intrínsecos de una concepción puramente circular de la relacionalidad.

Al final, el funcionalismo pone de manifiesto sus verdaderos límites como lectura de la sociedad dentro de la modernidad. Nacido con la modernidad, muere con ella. En la actualidad, se es más consciente de las peculiares premisas culturales de una manera de entender la teoría y la práctica social. Esta, a la par que nos ha enriquecido notablemente con muchos insights y precisos métodos de investigación, tiene enormes dificultades cuando quiere constituir una explicación y comprensión del gran desafio: la diferenciación entre lo humano y lo social.

¿Podrá el funcionalismo reintroducir en su interior distinciones con el no-funcionalismo?: creo que sí. No hay ninguna razón para pensar que el funcionalismo haya muerto. Lo que la sociología relacional reivindica es i) que la sociedad también es no-funcional y ii) que ésta no procede como progresiva funcionalidad. También lo no-funcional reintroduce distinciones con lo funcional. La perspectiva relacional plantea el problema de administrar adecuadamente esta dinámica comprensiva, lo que conlleva la necesidad de acceder a un framework más complejo, que incluya lo funcional, lo no-funcional y sus relaciones. Este es el sentido de la perspectiva relacional y de la intervención de redes.

El pensamiento de los neo-funcionalistas puede ayudar a desarrollar esta perspectiva. Ahora bien, hasta cierto punto. No hemos de olvidar que dicho 
pensamiento nos ofrece una particular visión de la sociedad emergente como sistema que se adapta y funciona.

Para el funcionalismo, el alcohólico y el toxicómano son unos desviados: se conciben e interpretan como roles (en Parsons) o sistemas de comportamiento (en Luhmann) no-funcionales ${ }^{15}$. Similar es la consideración que se tiene de cualquier persona socialmente débil, como el minusválido o el anciano aislado. Desde la perspectiva relacional, esta etiqueta, o adscripción a un rol o posición dis-funcional, no es legítima. Bien sea por motivaciones ligadas al análisis sociológico o a la intervención social, bien sea por la importancia de la distinción humano/no humano en la sociedad, según la perspectiva relacional todo no se puede, ni se debe, reconducir a la dicotomía funcional/no-funcional. Este es el sentido de la community care como ejemplo y ámbito típico de la intervención de redes ${ }^{16}$.

La teoría funcionalista nos ofrece muchos instrumentos lógico-conceptuales que se pueden utilizar para estudiar los límites entre lo funcional y lo nofuncional. Sin embargo, sólo expresan el punto de vista de quien los observa desde el sistema de referencia funcional. Dicho en otros términos, la perspectiva funcionalista es un modo de formular teorías de la sociedad como mercado (Gesellschaft) y no teorías de la comunidad (Gemeinschaft). Tampoco puede ser una teoría de las inter-relaciones entre comunidad y sociedad. Para un análisis relacional, en concreto de los nexos comunidad/sociedad, es decir, de las redes, también es necesario saber ubicarse en el sistema de referencia externo, es decir, en lo no-funcional.

\section{CONCLUSIONES}

La perspectiva relacional, que se puede desarrollar teniendo en cuenta las aportaciones de la sociología funcional, constituye una teoría más rica y al mismo tiempo más diferenciada respecto a las otras teorías sociológicas que, tras un atento examen, se presentan unilaterales, reductivas, abstractas o empíricas.

\footnotetext{
${ }^{15}$ La diferencia entre la forma de plantear lo no-funcional en Parsons y en Luhmann es muy interesante. Distanciándose de Parsons, Luhmann elimina la distinción normativa normal/patológico y concibe el orden social como continua generación de desorden; sin embargo, para los dos, el malestar, la marginación, la patología social no tienen un sujeto humano, en cuanto que se trata —-según ellos- de manifestaciones sistémicas (del sistema social en inter-relación con el sistema psíquico y, si acaso, con el sistema biológico, sin referencias al sistema cultural).

${ }^{16}$ Entre las más recientes publicaciones, veánse: P. Di Nicola (1990), L. Sanicola (1990), F. Folgheraiter, P. Donati (1991), M. Herrera (1998), C. Alemán Bracho y M. García Serrano (1999).
} 
En sociología, el sentido de la vía relacional está más en incluir que en excluir. Aún más, tendríamos que decir que la vía relacional se auto-concibe como teoría que incluye y excluye según recorridos dotados de sentido mediante la ubicación de la relacionalidad en el nivel de primera presuposición (en el ámbito metafísico) de la sociología como ciencia. En concreto, continuamente reintroduce la diferencia entre sentido humano/no humano en lo social. Al obrar de esta forma promete una mejor comprensión de los términos (por ejemplo, sujeto humano/no humano) de la relación. De ellos se propone dar cuenta en términos abiertos y dinámicos mediante una óptica que, como parte constitutiva de la identidad de los términos, protege y promueve su relativa (es decir, recíproca) autonomía. Para alcanzar este objetivo se debe desarrollar un análisis que no separe lo que es producto artificial (histórico, social, contingente) de lo que, aun estando inmerso en tal ambiente, tiene sus raíces en la vida pre y meta-social.

Ha empezado un nuevo desafio entre hombre y sociedad. El humanismo del pasado ya no tiene validez. La sociedad contemporánea tiende a construir un sistema social que pueda prescindir de lo humano: el intento es evitar problemas de conciencia, de motivaciones interiores y de intencionalidades significativas; en última instancia, de evitar una producción de sentido por parte de los sujetos. No es que se elimine lo humano, sino que se le ubica en el ambiente del sistema, como lo que puede fluctuar a placer, libre de pensar y activar comportamientos irracionales e inmorales. No en vano, el hombre del funcionalismo no es ya el parámetro con el que se puede medir la sociedad, y, viceversa, la sociedad no es ya ipso facto humana.

Esta perspectiva admite la existencia de una estructura social que no sólo permite al hombre salir y entrar en la sociedad, sino que - evolutivamentele empuja progresivamente a lo mismo. La liberación del hombre no tiene lugar dentro de la sociedad, sino por parte de la sociedad hacia el exterior (su ambiente indeterminado). La indeterminación del ambiente obliga al sistema a determinarse, pero la determinación del sistema (por ejemplo, la sociedad) aumenta la indeterminación de su ambiente.

¿Qué podemos decir de esta perspectiva, al mismo tiempo tan sugestiva y problemática? Si siguiéramos la lógica sistémico-funcionalista, admitiríamos que los problemas sociales sólo pueden afrontarse con organizaciones de welfare profesionalizadas y diferenciadas funcionalmente, es decir, a partir de factores técnicos. No resulta arriesgado decir que nos encontramos ante una respuesta parcial. A los grandes límites intrínsecos que poseen las organizaciones formales hay que añadir la negación y el rechazo que se realiza de todo lo que se ubica fuera de ellas. Este es el punto de partida de la perspectiva de la intervención de redes, que reivindica el carácter humano, antes que funcional, de la sociedad: ésta, por el peso de los propios acontecimientos, tiene que basarse en una teoría de las relaciones sociales que las contemple como intrínsecamente 
(estructural y normativamente) constituidas de una intersección formal e informal, funcional y no-funcional.

La capacidad de desafío funcionalismo es enorme. No en vano, para esta perspectiva el hombre se transforma en un sujeto diferente a como es o como generalmente lo hemos representado; se hace otro respecto a la sociedad, así como la sociedad se hace otra respecto a lo humano. Reivindicar la importancia de la subjetividad y de la cultura, transmitida y re-elaborada por la acción humana, como factores autónomos del cambio, es progresivamente más esencial aunque parezca una insensatez en el interior de la mentalidad sistémico-funcionalista. Los sistemas formales de servicio (sociales, sanitarios, etc.) tienden en la actualidad a actuar evitando problemas de motivación y elección. Dicho en otros términos, intentan confiar todo a sistemas técnicos que puedan evitar a las personas humanas (operadores y usuarios) el problema de activar recursos latentes y personalizados para la resolución del malestar y las patologías sociales, reprimiendo la valoración de los programas de bienestar y sus efectos.

He aquí el telón de fondo de este gran desafio: si el análisis y la intervención social pueden o no prescindir de una concepción de lo humano. La herencia final del funcionalismo consiste en la necesidad de elaborar separadamente una teoría de lo humano y una teoría de la sociedad. Para el funcionalismo la sociedad sólo puede ser humana parcialmente, es decir, sólo en algunas dimensiones (que deben entenderse como dimensiones analíticas o como reducciones) de su existencia más compleja.

La perspectiva de la sociología relacional acepta este desafío. Sin embargo, su lectura no sólo se hace desde la modernidad. Que el hombre no pueda reducirse a la sociedad, es algo que se sabe desde los albores de la civilización. El nuevo problema que debemos afrontar es el siguiente: debemos pensar que es la sociedad la que ordena al hombre (concebido como creciente indeterminación) o, por el contrario, que es el hombre el que ordena la sociedad. El neo-funcionalismo abandona esta segunda solución tachándola de ontológica. Por el contrario, la sociología relacional piensa que el hombre no puede dejar de orientar hacia sí el sentido de las relaciones sociales. Por ello, vive en las redes sociales, crea redes sociales, origina redes sociales, pero su existencia no está completamente determinada por ellas: las patologías sociales nacen cuando los sujetos están completamente atrapados en el interior de las redes. Por tanto, sólo una teoría adecuada de las redes puede permitirnos comprender qué distancia y gestión de las redes ayuda a liberar a los sujetos humanos de la trama de dichas redes. Por supuesto, sin negarlas o destruirlas, hecho este que sería inutil, salvo con estrategias de distancia, modificación, morfogénesis y diferenciación que reincorporen a lo humano. Explicar cómo se produce todo esto forma parte de la investigación empírica.

A pesar de que el funcionalismo parece liberar al hombre, en realidad propone una solución opuesta: el hombre es el producto de la sociedad, que puede 
ordenarlo como quiere en función de las selecciones admitidas por el estadio evolutivo alcanzado (porque el hombre se supone como ser indeterminado). Posteriormente intentará contemplar las consecuencias de este planteamiento. La solución no es novedosa, y las consecuencias no están libres de presuposiciones. Salir de esta trampa implica elaborar una representación de la sociedad distinta y compuesta, por así decir, de diferentes sociedades: la sociedad instrumentaladaptativa, la sociedad de los objetivos (fines como intereses) que se pueden perseguir, la sociedad de la integración social a través de mecanismos y reglas comunicativas, y la sociedad de la latencia, que evalúa y decide según valores y conciencia. Observar todo ello desde el punto de vista del sujeto humano que tiene que dotar de sentido las relaciones en que está sumergido constituye el nuevo horizonte que se abre con la post-modernidad: la sociedad de lo humano.

Teniendo presentes semánticas diferentes de las tradicionales, la sociedad de lo humano es aquélla que debe preguntarse, en cada nivel, en cada ámbito, como dimensión latente introducida en toda relación social, si los procesos sociales están operando o no de manera humana ${ }^{17}$. La sociedad de lo humano no es uno de los tantos mundos posibles, sino que es el mundo distintivo de lo humano: no es una sociedad idealmente soñada, sino que es la sociedad real en cuanto producida según la distinción humano/no humano. Para observar esta sociedad es necesario observar/pensar relacionalmente.

La perspectiva social que he intentado desarrollar en estas páginas, al mismo tiempo que se niega a interpretar los procesos societarios modernos en términos de relativismo epistemológico y de anulación del hombre, extrae su propia distinción-guía de una concepción de lo social que permite no perder las dimensiones específicas de lo humano. En una sociedad progresivamente más difícil y arriesgada, más incierta y desordenada, las disciplinas sociales alusivas a las políticas y a los servicios sociales deben buscar nuevas formas de caracterizar la existencia social, diferenciándola en humana y no-humana. Para llevar a cabo esta búsqueda es necesaria una brújula que oriente el conocimiento y la acción. Esta brújula es la relacionalidad de lo social y su adecuada representación en el plano del conocimiento teórico y práctico, histórico y ético. El que también pueda tener su lógica ${ }^{18}$ forma parte de la investigación del pensamiento reflexivo y de las prácticas de trabajo social, en una interacción recíproca.

En cualquier caso, si los conceptos (las realidades) de lo social deben ser interpretados desde un punto de vista humanista (desde el punto de vista del hombre), tendrán que relacionarse (redefinidos en relación) a la sociedad de lo humano. No podrán ser asumidos como humanos por el solo hecho de

${ }^{17}$ Como L de AGIL (Donati, 1991: cap.4).

${ }^{18} \mathrm{Me}$ refiero a una lógica, como la de AGIL. 
ser sociales. Lo humano tendrá que ser redescubierto en, y a través de, la relacionalidad que implica y exige. Este es el pilar fundamental, la premisa clave en la que se basa la sociología relacional.

\section{BIBLIOGRAFÍA}

ALEMÁN BRACHO, C. y M. GARCÍA SERRANO (1999), Fundamentos de Bienestar Social, Tirant lo Blanch, Valencia.

ALEXANDER, J. (1990), Teoria sociologica e mutamento sociale. Un'analisi multidimensionale della modernità, Angeli, Milán.

ARDIGÓ, A. (1988), Per una sociologia oltre il post-moderno, Laterza, Roma-Bari.

BATESON, G. (1966), "Critical Evaluations", International Journal of Psychiatry, n” 2, pp. 415-417.

BLAU, P. (1982), "Structural Sociology and Network Analysis", en P. Marsden y N. Lin (eds.), Social Structure and Network Analysis, Sage, Beverly Hills, pp. 217-252.

BLAU, P. y J. SCHWARTZ (1985), Crosscutting Social Circles. Testing a Macrostructural Theory of Intergroup Relations, Academic Press, Nueva York.

BOUDON, R. (1970), "Notes sur la notion de théorie dans les sciences sociales", European Journal of Sociology, XI, pp. 201-252.

BUCKLEY, W. (1982), La sociología y la teoría moderna de sistemas, Amorrortu, Buenos Aires.

BURT, R. S. (1982), Toward a Structural Theory of Action. Network Models of Social Structure, Perception, and Action, Sage, Bervely Hills.

CASTÓN BOYER, P. (1996), "La sociología de Pierre Bourdieu”, REIS, n 76, pp. 75-97.

COLEMAN, J. (1990), Foundations of Social Theory, Harvard University Press, Cambridge (Mass.).

CONSTABLE, R. (1992), "Relazionalità e appartenenza: fondamenti per una riflessione etica sul lavoro sociale", en F. Villa (comp.), Dimensioni del servizio sociale, Franco-Angeli, Milán.

COOK, W. y A. DREYER (1984), "The Social Relations Models", Journal of Marriage and the Family, vol. 46, no. 3, pp. 679-687.

COPI, I. y R. W. BEARD (1996), "Essays on Wittgenstein's Tractatus”, Londres.

DAVIS, K. (1959), "The Myth of Functional Analysis as a Special Method in Sociology and Antropology", American Sociological Review, vol. 24, nº 6, pp. 757-772.

DI MAGGIO, P. (1992), "Nadel's Paradox Revisited: Relational and Cultural Aspects of 


\section{R I S}

Organizational Structure", en N. Nohria y R.G. Eccles (eds.), Networks and Organizations: Structure, Forms and Action, Boston (Maas.), pp. 118-142.

DI NICOLA, P. (1986), "L’uomo no é un insola. Le reti sociali primarie nella vita quotidiana", Angeli, Milán.

(1990), "Analisi e intervento di rete", La Ricerca Sociale, n 43, pp. 85-112.

(1998), Le reti come metafora dell'appartenenza. Analisi structurales e paradigma di rete, Angeli, Milán.

DONATI, P. (1984), Risposte alla crisi dello Stato Sociale, Angeli, Milán.

(1985), Introduzione alla sociologia relazionale, Angeli, Milán.

(1986), Le frontiere della politica sociale, Angeli, Milán.

(1989), La famiglia come relazione sociale, Angeli, Milán.

(1991), Teoria relazionale della societa, Angeli, Milán.

(1993), La cittadinanza societaria, Laterza, Roma-Bari.

(1993), "Pensamiento sociológico y cambio social: hacia una teoría relacional", REIS, n 63 , pp. 29-51.

(1994), "Sulla distinzione umano/non umano. Per una sociologia del duemila", El Mundo $3, n^{\circ} 2$, pp. 158-177.

(1998), Lezioni di sociologia, CEDAM, Padua.

DURKHEIM, E. (1928), El suicidio, Reus, Madrid.

(1964), Las reglas elementales del método sociológico, Dédalo, Buenos Aires.

(1965), Las reglas del método sociológico, Dédalo, Buenos Aires.

(1968), Las formas elementales de la vida religiosa, Schapire, Buenos Aires.

(1971), Le socialisme, PUF, París.

(1976), Pragmatismo y sociología, Schapire, Buenos Aires.

(1995), La división del trabajo social, Akal, Madrid.

EKEH, P.P. (1974), Social Exchange Theory: The Two Traditions, Harvard University Press, Cambridge (Maas).

EMIRBAYER, M. (1997), "Manifiesto for relational sociology", American Journal of Sociology, 103, 2, pp. 281-317. 
FOERSTER, H. (von), (1984), Observing Systems, Intersystems Publ., Seaside, California.

FOLGHERAITER, (1994), Operatori sociali elevoro di rete, Erickson, Trento.

FOLGHERAITER, P. y P. DONATI (1991), Community care. Teoria y pratica del lavoro sociale di rete, Ediciones Centro Studi Erickson, Trento.

FORSÉ, M. (1991), “Les rèseaux de sociabilité: un état des lieux”, L'Année Sociologique, 41, pp. $245-264$.

(1993), "La fréquence des relations de sociabilité: typologie et évolution", L'Année Sociologique, $\mathrm{n}^{\circ} 43$, pp. 189-212.

FREUN, J. (1990), "Relation et activité sociale", Etudes Sur Max Weber, Ginebra-Paris, cap. III.

GADAMER, H. G. (1980), Verdad y Método, Sígueme, Salamanca.

GALLINO, L. (1978), Dizionario di sociologia, Utet, Turín.

GARFINKEL, H. (1967), Studies in Ethomethodology, Englowood Cliffs, N.J.

GEHLEN, A. (1983), Antropologia filosofica e teoria dell'azione, Guida, Nápoles.

GEERTZ, C. (1995), La interpretación de las culturas, Gedisa, Madrid.

GIDDENS, A. (1979), New Rules or Sociological Theory, MacMillan, Londres.

GOFFMAN, E. (1967), Interaction Ritual, Garden City, Nueva York.

(1969), Strategic interaction, Filadelfia.

(1974), Frame analysis, Hamper and Row, Nueva York.

GOTTMAN, J.M. (1982), "Temporal Form: Toward a Neu Languaje for Describing Relations-hips", Journal of Marrige and the family, 44, 4, pp. 943-962.

GRAMSCI, A. (1951), "Gly intellettuali e L'organizzazione della cultura", Quaderni dal Carcere, Einaudi, Turín.

GOULDNER, A. (1979), La sociología actual: renovación y crítica, Alianza, Madrid.

GURVITCH, G. (1950), La vocation actuelle de la sociologie, París.

GUBRIUM, J. F. (1988), "The Family as project", The Sociological Review, vol. 36, n. 2, pp. 85-97.

HABERMAS, J. (1987), Teoría de la acción comunicativa, Taurus, Madrid.

HADDEN, R. W. (1988), "Social relations and the content of early modern science", The British 


\section{RIS}

REIISTA INTERNACIONAL DE SOCIOLOGLIA

N" 28. Enero - Abril. 2001

Journal of Sociology, 39, 2, pp. 255-280.

HÉRAN, F. (1988), "Au coeur du réseaux associtif: les multi-adhérents", Economie et Stadistique, 208, Mars, pp. 33-44.

(1988), "La sociabilité, une practque culturelle", Economie et Stadistique, 216, Decembre, pp. 3-22.

HERRERA, M. (1998), "Nuevos desafios en politicas sociales: la community care", REIS, $n^{\circ} .82$, pp. $43-72$.

HEWITT, C. (1984), The Challenge of Open Systems, Mit. Cambridge, Ma.

HORSTMANN, R.P. (1984), Ontologie und Relationen. Hegel, Bradley, Russel und die Kontroverse ïber interne und externe Beziehungen, Hain Königstein.

HUSSERL, E. (1962), Ideas, FCE, México.

HUSTON, T. y E. ROBINS (1982), "Conceptual and Methodological Issues in Studying Close Relationships", Journal of Marriage and the family, vol. 44, $\mathrm{n}^{\circ} 4$.

IGLESIAS DE USSEL, J. (1987), "El tiempo en la sociedad contemporánea", Politica y Sociedad. Estudio en homenaje a Francisco Murillo Ferrol, vol. I, CIS/Centro de Estudios Constitucionales, Madrid, pp. 113-133.

KENEY, B. P. (1983), Aesthetics of Change, Nueva York-Londres.

KREMPEL, A. (1952), "La Doctrine de la relation chez Saint Thomas", Exposé historique et systématique, Vrin, Paris.

LAUMAN, E. y P. MARSDEN (1983), "The Boundary Specification Problem in Network Analysis", en R. Burt y M. Minor (eds.), Applied Network Analysis, Sage, Beverly Hills.

LÉVI-STRAUSS, C. (1967), Le structture della parentela, Feltrinelli, Milán.

LORIEDO, C. (1978), Terapia relazionale, Astrolabio, Roma.

LUHMANN, N. (1983), "Mutamento di paradigma nella teoria dei sistemi", Sistemi Urbani, no. 2, pp. 333-347.

(1984), Soziale Systeme, Frankfurt.

(1989), "Il sistema sociale famiglia", La Ricerca Sociale, n 39, pp. 75-91.

(1993), “Perché AGIL?”, Teoría Sociológica I, nº1, pp. 157-175.

(1998), Sistemas sociales: Lineamientos para una teoria general, Anthropos, Barcelona.

MARX, C. (1961), El Capital, vols. I, II, III, FCE, México.

42 
(1968), "Prólogo", en F. Engels, Filosofia del Derecho, Claridad, Buenos Aires.

(1968), La Ideologia alemana, Pueblos Unidos, Montevideo.

(1969), Manuscrito: Economia y Filosofia, Alianza, Madrid.

MATURANA, H. (1980), Autopoiesis and cognition: the realization of the livign, Dordrecht, Boston.

MATURANA, H. y F. VARELA (1990), El árbol del conocimiento: las bases biológicas del conocimiento humano, Debate, Madrid.

MAUSS, M. (1950), Sociologie et Antropologie, PUF, París.

MAYURAMA, M. (1963), "The Second Cybernetics: Deviation-Amplifying Mutual Casual Processes”, American Scientist, vol. 51, pp. 164-179.

McLUHAM, M. (1964), Understanding media, Signet, Nueva York.

MEAD, G.H. (1934), Mind, Self and Society from the Standpoint of a Social Behaviorst, Chicago.

(1977), “On Social Psychologi”, Selected Papers, Chicago University Press, Chicago.

MELUCCI, A. (1984), Altri codifi. Aree di movimento nella metropoli, Il Mulino, Bolonia.

MERTON, R. (1972), Teoría y estructura social, Fondo de Cultura Económica, México.

MIRALBELL, I. (1994), El dinamismo voluntarista de Duns Escoto. Una transformación del aristotelismo, Eunsa, Pamplona.

MORENO, J.L. (1953), Who shmall Survive?, Beacon House, Nueva York.

(1956), Sociometry and Science of Man, Beacon House, Nueva York.

MORIN, E. (1980), La vie de la Vie, De du Seuil, París.

(1986), La connaissance de la connaissance, De du Seuil, París.

(1987), Scienza con coscienza, Angeli, Milán.

(1997), La nature de la nature, De du Seuil, París.

PARETO, V. (1932), Tratité de sociologie générale, Payut, París.

PARSONS, T. (1984), El sistema social, Alianza, Madrid.

PIEPER, J. (1981), “La verità delle cose”, Studi Cattolici, nº 250, pp. 147-165. 
RIS

RETISTA INTERNACIONAL DE SOCIOLOGI.

N" 28. Enero - Albril. 2001

RICOEUR, P. (1989), Dal testo all'azione, Jaca Book, Milán.

SANICOLA, L. (1990), Comunità e servizi alla persona, Cedam, Padua.

TAM, T. (1989), "Demarcating Boundaries Between Self and the Social: The Anatomy of Centrality in Social Networks", Social Networks, vol. 11, n 4, pp. 388-400. 